Metallurgical Transactions B, Vol. 24B, No. 2 (April), 1993, pp. 379-393.

\title{
Modeling of Steel Grade Transition in Continuous Slab Casting Processes
}

\author{
X. Huang and B. G. Thomas \\ Department of Mechanical and Industrial Engineering \\ University of Illinois at Urbana-Champaign \\ 1206 West Green Street \\ Urbana, IL 61801
}

\begin{abstract}
Mathematical models have been developed and applied to investigate the composition distributions that arise during steel grade changes in the continuous slab casting processes. Three-dimensional turbulent flow and transient mixing phenomena in the mold and the strand were calculated under conditions corresponding to a sudden change in grade. The composition distribution in the final slab was then predicted. Reasonable agreement was obtained between predicted and experimental concentration profiles in the slab centerlines. Intermixing in the center extends many meters below the transition point while intermixing at the surface extends above. Higher casting speed increases the extent of intermixing. Mold width, ramping of casting speed, and nozzle design have only small effects. Slab thickness, however, significantly influences the intermixing length of the slab. The axial transport of solute due to turbulent eddy motion was found to be many orders of magnitude greater than molecular diffusion and thus dominates the resulting composition distribution. Different elements, therefore, exhibited the same mixing behavior under the same casting conditions, despite having different molecular properties. Numerical diffusion caused by the finite difference schemes was investigated and confirmed to be much less important than turbulent diffusion. In the lower portion of the strand (lower than 3 meters below the meniscus), the convection and diffusion can be reasonably approximated as one dimensional axial flow.
\end{abstract}




\section{INTRODUCTION}

As the efficiency and flexibility of the continuous casting process improves, it is becoming increasingly common to cast different grades of steel as successive heats in a single casting sequence. Unfortunately, mixing tends to occur during the transition between steel grades. Slabs cast during the transition vary in composition between the grade of the first heat, or "old grade" and that of the second heat, or "new grade," in the sequence. The final product is often referred to as "intermixed steel" and is naturally undesirable since it must be downgraded. The cost can be significant, since each meter of intermixed slab length contains roughly 2 tonnes of steel.

The continuous casting process is illustrated in Figure 1. In this work, the term "strand" refers to the solidifying shell containing the liquid steel while it travels down through the continuous casting machine. The "slab", which is the final solid product, does not exist until the strand is completely solid and has been cut into pieces at the torch cutoffpoint.

Mixing in the mold and the strand are governed by two phenomena. The first is mass transport or convection due to the mean flow velocities, which depend directly on the casting speed. The second is diffusion due to turbulent eddy motion and random molecular motion. Generally, the turbulent component is much more important than the molecular one due to the high turbulence in most region of the liquid pool within the shell.

Several different ways have been developed to minimize the extent of the intermixing region during grade transitions. The most effective way is to insert a physical barrier into the mold between the two heats. ${ }^{[1]}$ Steel freezes around the steel barrier, which is often shaped like an I to help hold the two strands together. This essentially prevents any mixing of the two grades. However, this method requires the casting process to be slowed down or even stopped for a significant time, which risks damaging the strand or even the casting machine. There is also an increased risk of breakouts compared with other methods.

The most common method is simply to change ladles and carefully track and downgrade the intermixed slabs, according to the severity of the composition change due to the mixing. Sequence casting is then completely unaffected by composition changes. The disadvantage of this method is that significant mixing occurs in the tundish, in addition to the strand. Thus, several slabs containing many tonnes of intermixed steel are created. 
Another common method, the "flying tundish change", is used to reduce the amount of intermixed steel generated. ${ }^{[2,3,4]}$ By changing the tundish simultaneously when changing ladles to a new grade, mixing occurs only in the strand. To accomplish the tundish change, the casting speed must always be slowed down considerably. The casting speed is then increased gradually or "ramped" back to its normal setting over several minutes, as shown in Figure 2 for an idealization of a typical practice.

The present work was undertaken to investigate mixing in the strand, focusing specifically on the flying tundish change method of grade transition. The objective is to develop and apply a mathematical model to predict quantitatively the extent of mixing in both the strand and slab as a function of casting conditions. By providing insight into mixing phenomena in the continuous casting process in general, this work should also be of interest even when the tundish is not changed with every grade change.

Most of the existing work on grade transition has focused on mixing in the tundish, using both empirical methods and model calculations. Lowry and Sahai ${ }^{[5]}$ measured how the tracer concentrations evolved with time in a tundish. Burns et al. ${ }^{[6]}$ developed a model to evaluate the compositions at the outlet of the tundish, based on measurements of slab

surface composition and liquid samples taken from the mold. Mannion et al. ${ }^{[7]}$ developed an empirical model to calculate the relation between the compositions and the poured steel weight in the tundish, assuming that the composition is constant in transverse crosssections. None of above-mentioned work has considered mixing in the strand.

Mathematical models of mass transfer in the continuous casting tundish have also been developed. Tsai and Green ${ }^{[8]}$ investigated this using a 3-D finite difference model to develop a relation between tundish transition time, tundish level and casting rate. Finite difference models have also been used to investigate tracer diffusion and mixing in the tundish. $[9,10,11]$

\section{3-D MASS TRANSFER MODEL OF UPPER STRAND}

Three separate finite difference models have been developed in the present work, which together enable the calculation of composition in the entire continuous casting strand and slab after a sudden grade change. The first model calculates 3-D transient turbulent fluid flow and solute diffusion in the strand. This model simulates only the first $6 \mathrm{~m}$ of the strand below the meniscus. For economy, the remaining $20-40 \mathrm{~m}$ to the point of final solidification are modeled using a 1-D model described in the next section. Diffusion in the solid is ignored. The third model then converts the 3-D composition-time distributions 
from the first two models into composition-distance distributions in the final slab, according to an assumed parabolic rate of shell growth. The second and third models are discussed in Sections III and IV respectively.

Figure 3 shows the $60 \times 34 \times 16$ grid of nodes used by the first model to simulate the first $3 \mathrm{~m}$ of the liquid pool in the present work. A second $60 \times 34 \times 16$ grid of nodes, which is uniform in z-direction (casting direction), was adopted from $3 \mathrm{~m}$ to $6 \mathrm{~m}$ below the meniscus. Two-fold symmetry is assumed so only one quarter of the physical strand is modeled. The effect of any gradual curvature of the strand is ignored, since it is believed to be small. The transient diffusion model calculates compositions in this $6 \mathrm{~m}$ domain by solving the 3-D transient diffusion equation*

*Symbols and their standard values are defined in Table I.

$$
\frac{\partial \mathrm{C}}{\partial \mathrm{t}}+\mathrm{v}_{\mathrm{x}} \frac{\partial \mathrm{C}}{\partial \mathrm{x}}+\mathrm{v}_{\mathrm{y}} \frac{\partial \mathrm{C}}{\partial \mathrm{y}}+\mathrm{v}_{\mathrm{z}} \frac{\partial \mathrm{C}}{\partial \mathrm{z}}=\frac{\partial}{\partial \mathrm{x}}\left(\mathrm{D}_{\mathrm{eff}} \frac{\partial \mathrm{C}}{\partial \mathrm{x}}\right)+\frac{\partial}{\partial \mathrm{y}}\left(\mathrm{D}_{\mathrm{eff}} \frac{\partial \mathrm{C}}{\partial \mathrm{y}}\right)+\frac{\partial}{\partial \mathrm{z}}\left(\mathrm{D}_{\mathrm{eff}} \frac{\partial \mathrm{C}}{\partial \mathrm{z}}\right)
$$

where $\mathrm{C}$ is the dimensionless composition, or "relative concentration" defined by:

$$
\mathrm{C} \equiv \frac{\mathrm{F}(\mathrm{x}, \mathrm{y}, \mathrm{z}, \mathrm{t})-\mathrm{F}_{\text {old }}}{\mathrm{F}_{\text {new }}-\mathrm{F}_{\text {old }}}
$$

and $\mathrm{F}(\mathrm{x}, \mathrm{y}, \mathrm{z}, \mathrm{t})$ is the fraction of a given element at a specified position in the strand or slab; $F_{\text {old }}$, and $F_{\text {new }}$ are the desired fractions of that element in old and new grades respectively.

A 3-D fluid flow model was used to calculate the velocities $v_{x}, v_{y}$ and $v_{z}$ needed in the above equation, by solving the continuity, 3 momentum and 2 turbulence equations given in Appendix I and II. Composition changes occurring during the grade transition change only the molecular properties, which have been found to have a negligible effect on flow velocities. ${ }^{[12,13]}$ Therefore, fluid flow can be assumed to be steady, incompressible, turbulent, single-phase Newtonian flow when no change in casting speed occurs. Further discussion of how this fluid flow model works and comparisons of the model results with water model observations and measurements are given elsewhere. ${ }^{[12,13]}$

The Reynolds number in the caster, based on the hydraulic diameter, (Table I) always exceeds 10,000 even far below the mold. This indicates that the flow is highly turbulent everywhere. Thus, the K- $\varepsilon$ turbulence model is used in calculating velocities. [13] In addition, diffusion is enhanced greatly by turbulent eddy motion, so the effective diffusivity, $\mathrm{D}_{\mathrm{eff}}$, consists of both molecular and turbulent components: 


$$
D_{\text {eff }}=D_{0}+\frac{\mu_{t}}{\rho S c_{t}}
$$

It is important to note that the effective diffusivity depends greatly on the turbulence parameters through the calculated turbulent viscosity, $\mu_{\mathrm{t}}$, defined in Appendix I, and the turbulent Schmidt number, $\mathrm{Sc}_{\mathrm{t}}$, which is set to 1 in the present work, as commonly practiced. $[10,11,14,15]$

\section{A. Initial Conditions}

The fluid flow is steady state if there is no ramping or other change of the casting speed. The transient effects on the flow pattern during ramping are taken into account by a special treatment described in next section. The initial conditions on velocity are taken from the steady-state solution for the normal casting speed.

Arbitrary composition changes between successive grades can be studied through relative concentration changes of two elements, A and B. Those elements whose compositions decrease from the old grade to the new grade are represented by "element A". Elements which increase between successive heats in a sequence are represented by "element B". A constant initial condition is imposed on relative concentration:

$$
\mathrm{t} \leq 0: \quad \mathrm{C}= \begin{cases}1 & \text { for element } \mathrm{A} \\ 0 & \text { for element } \mathrm{B}\end{cases}
$$

\section{B. Boundary Conditions}

\section{Inlet:}

The mold cavity is fed by a bifurcated, submerged entry nozzle, which has an important influence on the flow pattern. To account for this, the velocity components, $\mathrm{v}_{\mathrm{X} 0}$, $\mathrm{v}_{\mathrm{y} 0}$ and $\mathrm{v}_{\mathrm{z} 0}$, and the turbulence parameters, $\mathrm{K}$, and $\varepsilon$, are fixed at the inlet plane to the mold cavity. The normal component, $\mathrm{v}_{\mathrm{x} 0}$, is linked to the casting speed and is given either a constant value or a parabolic profile, increasing from 0 at the top to its peak value at the bottom of the inlet plane. The vertical component, $\mathrm{v}_{\mathrm{Z} 0}$, which is linked to the initial jet angle, is given the same way as $\mathrm{v}_{\mathrm{x} 0}$, and the horizontal component $\mathrm{v}_{\mathrm{y} 0}$, which is linked to the spread angle, is set to zero. The inlet plane dimensions, $\mathrm{L}_{\mathrm{h}}$ and $\mathrm{L}_{\mathrm{W}}$, correspond to the area of the nozzle port where steel flows outward. Because a relative stagnant region exists in the top portion of typical oversized ports of nozzles used in service, ${ }^{[16,17]} \mathrm{L}_{\mathrm{h}}$ is shorter 
than the actual height of the nozzle port. The values defining flow through the inlet, $\mathrm{v}_{\mathrm{x} 0}, \mathrm{v}_{\mathrm{y} 0}$ and $\mathrm{v}_{\mathrm{z} 0}, \mathrm{~K}, \varepsilon, \mathrm{L}_{\mathrm{h}}$ and $\mathrm{L}_{\mathrm{w}}$ are given in Table $\mathrm{I}$ and correspond to conditions at the exit plane from the nozzle port. They are calculated using a separate model of fluid flow in the nozzle, described elsewhere. ${ }^{[16,17]}$

Relative concentration of element A simply decreases suddenly from 1 to 0 across the inlet plane (nozzle exit) at the time instance when the transition starts. The inlet concentration is kept at this value 0 afterwards. This corresponds to an ideal "flyingtundish change" operation. Relative concentration of element B is the reverse of A:

$$
\mathrm{t}>0: \quad \mathrm{C}= \begin{cases}0 & \text { for element A } \\ 1 & \text { for element B }\end{cases}
$$

\section{Outlet, Symmetry Planes, and Top Surface}

Because calculations are performed with the 3-D model only in the top portion of the liquid pool, an artificial outlet plane is created where flow leaves the domain. Across this bottom outlet plane, normal gradients $(\partial / \partial \mathrm{z})$ of all variables, including $\mathrm{v}_{\mathrm{X}}, \mathrm{v}_{\mathrm{y}}, \mathrm{v}_{\mathrm{z}}, \mathrm{K}, \varepsilon$, and $\mathrm{p}$ are set to zero. The same boundary conditions are used for each node on a symmetry centerplane, except that the velocity component normal to the symmetry plane is set to zero. The top surface is treated as a symmetry plane.

Zero-gradient or "no mass diffusion" boundary conditions were imposed on relative concentration at the outlet plane, the symmetry planes and the top surface:

$$
\mathrm{t}>0: \frac{\partial \mathrm{C}}{\partial \mathrm{n}}=0
$$

\section{Other Boundaries}

Because the model domain is the entire strand, Eq. [6] is also imposed at the other boundaries, which correspond to the strand surface. This prevents solute from leaving the domain at these boundaries. For computational convenience, the models simulate both the solid and liquid, using liquid properties everywhere. The error induced by this approximation is not significant because results calculated in the solid are never used in the slab calculations (to predict slab composition).

\section{Ramping of Casting Speed}


To account for the effect of ramping the casting speed on the flow pattern, without incurring huge expenses in modeling 3-D transient turbulent fluid flow, a compromise approach is utilized in the present work. At each time step, the steady-state velocity solution was scaled uniformly by the ratio of the current inlet velocity to the steady-state value. This approach relies on two reasonable assumptions. Firstly, the steady-state flow pattern (streamlines) does not vary with speed or Reynolds number when the flow is fully

turbulent. ${ }^{[13]}$ Secondly, the transient pressure wave moves at the acoustic speed, ${ }^{[18]}$ so should propagate the effect of the new inlet velocities throughout the mold almost immediately. The casting speed curve used in the present work is shown in Figure 2, which approximates that used in practice. ${ }^{[2]}$

\section{Solution method}

\section{Fluid Flow Velocities}

Owing to the regular rectangular geometry of the mold, a computer code based on finite difference calculations, MUPFAHT ${ }^{[19]}$ was used to solve the steady-state (elliptic) system of differential equations and boundary conditions, which describe this problem. The finite difference equations use a staggered grid and seven-point stencil of control volumes, discretized spatially using a hybrid scheme which generally has second-order accuracy but automatically switches to a first-order upwinding scheme in domains with high cell Reynolds number. ${ }^{[20]}$ In addition, the source terms are linearized to increase diagonal dominance of the coefficient matrix. ${ }^{[20]}$ The equations are solved with the Semi-Implicit Method of Pressure-Linked Equations algorithm, whose ADI (Alternating-Direction-semiImplicit) iteration scheme consists of 3 successive TDMA (Tri-Diagonal-Matrix-Algorithm) solutions (one for each coordinate direction) followed by a pressure-velocity-modification to satisfy the mass conservation equation [A-1.1]. ${ }^{[20]}$ 
Obtaining reasonably-converged velocity and turbulence fields for this problem is difficult, owing to the high degree of recirculation. The current strategy employed is successive iteration using an under-relaxation factor of 0.2 or 0.3 until the maximum relative residual error and maximum relative error between successive solutions falls below 0.1 pct. Over 2500 iterations are required to achieve this, starting from an initial guess of zero velocity, which takes about $30 \mathrm{CPU}$ hours on an SGI (Silicon Graphics 4D/25 workstation). For subsequent processing conditions, convergence from a previouslyobtained solution is faster. Results were visualized using the FIDAP post processor ${ }^{[21]}$.

\section{Mass Transfer}

The 3-D transient diffusion equation is solved after the velocity solution has been obtained, since it can be uncoupled. This solution is obtained using the backward Eulerian method, which is a full implicit scheme for time discretization. Variable time step increments were taken as:

$$
(\Delta \mathrm{t})_{\mathrm{n}+1}=(\Delta \mathrm{t})_{\mathrm{n}}\left(\frac{\mathrm{e}_{\mathrm{a}}}{\mathrm{e}_{\mathrm{n}}}\right) \frac{1}{2}
$$

where $(\Delta \mathrm{t})_{\mathrm{n}+1}$, and $(\Delta \mathrm{t})_{\mathrm{n}}$ are time increments at the current and previous time steps respectively; $\mathrm{e}_{\mathrm{a}}$ is the allowable relative time truncation error of the equation, which was usually set to $0.1 \mathrm{pct}$; and $\mathrm{e}_{\mathrm{n}}$ is the relative time truncation error of the equation at the previous time step. Within each time step, usually several hundred ADI TDMA iterations

are needed to reach convergence. A simulation of $960 \mathrm{~s}$ of casting requires about 50 time steps and 8 hours of CPU time on the SGI.

\section{1-D MASS TRANSFER MODEL OF LOWER STRAND}

The point of final solidification, the "metallurgical length", is found about $20 \mathrm{~m}$ from the meniscus, or further depending on the casting speed, which takes a given position in the strand about $1200 \mathrm{~s}$ to reach. Therefore, composition evolution for this time period must be calculated over this entire domain of the strand before it is possible to predict the complete composition distribution in the final slabs. A huge number of grid nodes would be needed for the 3-D model to obtain these reasonable results. On the other hand, the initial 3-D results for the top $6 \mathrm{~m}$ show that the velocity profile in the lower region of the strand is quite uniform and close to that of turbulent flow through a duct. Furthermore, the composition profile is almost uniform in the transverse section. Based on this knowledge, a 
1-D mass transfer model was developed and applied below the point, $\mathrm{Z}_{1}$, usually chosen to be $6 \mathrm{~m}$ down the strand. For this 1-D model, Eq. [1] simplifies to:

$$
\frac{\partial \mathrm{C}}{\partial \mathrm{t}}+\mathrm{v}_{\mathrm{z}} \frac{\partial \mathrm{C}}{\partial \mathrm{z}}=\mathrm{D}_{\mathrm{eff}} \frac{\partial^{2} \mathrm{C}}{\partial \mathrm{z}^{2}}
$$

and $\mathrm{D}_{\text {eff becomes constant. }}$

The velocity solution is simply:

$$
\mathrm{v}_{\mathrm{z}}=\mathrm{v}_{\mathrm{z} 1}(\mathrm{x}, \mathrm{y}, \mathrm{t})
$$

The initial and boundary conditions for relative concentration are:

$$
\begin{array}{ll}
\mathrm{t} \leq 0: & \mathrm{C}=\left\{\begin{array}{cc}
1 & \text { for element } \mathrm{A} \\
0 & \text { for element } \mathrm{B}
\end{array}\right. \\
\mathrm{z}=\mathrm{Z}_{1}, \mathrm{t}>0: & \mathrm{C}=\mathrm{C}_{1}(\mathrm{x}, \mathrm{y}, \mathrm{t}) \\
\mathrm{z}=\mathrm{Z}_{\text {final }}, \mathrm{t}>0: & \frac{\partial \mathrm{C}}{\partial \mathrm{z}}=0
\end{array}
$$

where $\mathrm{v}_{\mathrm{z} 1}(\mathrm{x}, \mathrm{y}, \mathrm{t})$ and $\mathrm{C}_{1}(\mathrm{x}, \mathrm{y}, \mathrm{t})$ are the inlet boundary conditions, specified from 3-D model predictions of the velocity and concentration distributions at the outlet of the upper domain $\left(\mathrm{Z}_{1}=6 \mathrm{~m}\right.$ below the meniscus $)$.

Equations [8] through [12] were solved with the same time integration and spatial difference schemes used for the 3-D model. It took only about $120 \mathrm{~s}$ CPU time on the SGI, with an 800 node mesh of a $14 \mathrm{~m}$ long domain.

Because of its computational efficiency, the 1-D model was later extended to evaluate the entire composition history along the centerline from the meniscus without use of 3-D results for the upper $6 \mathrm{~m}$. For these runs, the turbulent diffusivity was enhanced 15 times in top $3 \mathrm{~m}$ of the strand to account for the effects of 3-D flow. In addition, $\mathrm{v}_{\mathrm{z} 1}$ was set to the casting speed, which depends only on time. The boundary condition Equation [11] was changed to:

$$
\mathrm{z}=0, \mathrm{t}>0: \quad \mathrm{C}= \begin{cases}0 & \text { for element } \mathrm{A} \\ 1 & \text { for element } \mathrm{B}\end{cases}
$$




\section{SLAB COMPOSITION MODEL}

The composition distribution in the final slab develops as the solidifying shell grows in thickness down the caster. The third model of this work calculates these composition distributions in the final slab based on the 3-D, time-varying concentration history of the strand, generated by the first two models. Composition at each point in the strand is assumed to evolve according to the calculated history until that point solidifies. The composition is assumed to remain constant thereafter, so that diffusion in the solid is ignored. In the time available, (less than $3000 \mathrm{~s}$ ), the maximum solid diffusion distance would be only a few millimeters, so this approximation is reasonable.

Expressed mathematically, this model performs a coordinate transformation on the strand results, $\mathrm{C}$, to obtain the composition in the final slab, $\mathrm{C}_{\mathrm{slab}}$ :

$$
\mathrm{C}_{\mathrm{slab}}\left(\mathrm{x}_{\mathrm{S}}, \mathrm{y}_{\mathrm{s}}, \mathrm{z}_{\mathrm{S}}\right)=\mathrm{C}(\mathrm{x}, \mathrm{y}, \mathrm{z}, \mathrm{t})
$$

where the spatial and time coordinates in the strand, $\mathrm{x}, \mathrm{y}, \mathrm{z}$, and $\mathrm{t}$, are related to the coordinates in the final slab, $\mathrm{x}_{\mathrm{s}}, \mathrm{y}_{\mathrm{s}}, \mathrm{z}_{\mathrm{s}}$, through the following equations:

$$
\begin{aligned}
& x=x_{s} \\
& y=y_{s} \\
& z=\int_{0}^{t_{s}} v_{z} d t \\
& t=\int_{z_{S}}^{z} \frac{d z}{v_{z}}
\end{aligned}
$$

The $t_{\mathrm{s}}$ in Eq. [17] represents the solidification time of the steel shell, which is defined when the composition at a given depth beneath the strand surface no longer changes. To specify $t_{s}$, a simple relationship between position in the strand, shell thickness $\Delta \mathrm{L}$ and $\mathrm{t}_{\mathrm{s}}$ was assumed:

$$
\mathrm{t}_{\mathrm{s}}=\left(\frac{\Delta \mathrm{L}}{\mathrm{k}_{\text {shell }}}\right)^{2}
$$




$$
\Delta \mathrm{L}=\min \left(\frac{\mathrm{W}}{2}-\mathrm{y}, \frac{\mathrm{N}}{2}-\mathrm{x}\right)
$$

The solidification constant, $\mathrm{k}_{\text {shell }}$, depends on spray cooling conditions at the strand surface and $0.00327 \mathrm{~m} \mathrm{~s}^{-0.5}$ is typical of values reported from previous measurements in the strand. It should be noted that Eq. [19] neglects any delays in the adjustment of the shell thickness to reach the new steady-state profile after a sudden change in casting speed. This might have a small effect at the beginning of ramping. The model also neglects the slight variation in $\mathrm{k}_{\text {shell }}$ that often accompanies a change in casting speed, due to corresponding changes in spray cooling practice and heat extraction rate.

\section{MODEL RESULTS}

Model calculations of velocity, composition in the strand and in the slab are now presented and compared with available measurements. The results were obtained by running the standard combination of three models, i.e. 3-D model for the top $6 \mathrm{~m}, 1-\mathrm{D}$ model for the rest of the strand, and slab composition model, all under standard casting conditions showed in Table I, except where otherwise indicated.

\section{A. Flow Pattern}

Figure 4 presents typical velocity predictions in the top $3 \mathrm{~m}$ portion of the strand. For presentation clarity, a velocity vector is drawn only at every eighth node. This figure views the centerline section and shows how flow leaves the nozzle as a strong jet, traveling across the mold to impinge upon the narrow face, then splitting vertically to create upper and lower recirculation regions. This turbulent flow pattern enhances the transport of mass, momentum and energy in the upper region of the strand. The figure also shows that velocity is quite uniform in the downstream region, 2.5 to $3 \mathrm{~m}$ below the meniscus. In the lower portion of the strand, steel moves vertically in the casting direction. By $6 \mathrm{~m}$ below the meniscus, the velocity solution closely approximates 1-D channel flow with an average velocity equal to the casting speed.

\section{B. Strand Composition}

The relative concentration distribution calculated in the first $6 \mathrm{~m}$ portion of the strand is revealed in Figure 5 at different time steps for $1 / 4$ of the strand. The figure depicts the evolution of relative concentration of element $\mathrm{B}$, which also indicates the fraction of new 
grade present. The isoconcentration contours shown in this figure outline the spread of element $\mathrm{B}$ due to the combined effects of convection and diffusion.

The jet brings steel containing 100\% relative concentration element B into the strand at the inlet. As the jet moves, it carries element B with it. Where the jet impinges the narrow face, it carries mass both upwards and downwards. At the same time, the strong turbulence causes mass diffusion in all directions. In the upper region, the narrow face shell sees the new steel grade first so that always has highest concentration of element B at any time. Combined with the upper recirculation zone, the upper portion of the mold very quickly approaches the composition of the new grade (rich in element B). At the meniscus, where the first solidification takes place and the composition of the slab surface is determined, the narrow surface has a slightly higher concentration of element B than the centerline of the strand, producing a slight concentration gradient across the mold width direction on the wide surface of the strand. This effect diminishes with time. Relative concentration across the meniscus is more than $95 \% \mathrm{~B}$ after $480 \mathrm{~s}$.

In the lower region of the strand, the isoconcentration lines in Figure 5 show behavior corresponding to the uniform velocity solution. They shift downward with time and become more uniform across the strand. Due to diffusion, they move slightly faster than the casting speed. The extra mean velocity due to this diffusion effect adds to the bulk average movement of steel and is called the "diffusion velocity", defined as:

$$
\mathrm{v}_{\text {diff }}=-\mathrm{D}_{\mathrm{eff}} \frac{\partial \mathrm{C}}{\partial \mathrm{z}}
$$

The diffusion velocity decreases as the concentration gradients reduce over time. For example, Figure 5 indicates that the 0.1 isoconcentration line shifts downward about $3.3 \mathrm{~m}$ from $\mathrm{t}=120 \mathrm{~s}$ to $300 \mathrm{~s}$, but only $2.8 \mathrm{~m}$ from $300 \mathrm{~s}$ to $480 \mathrm{~s}$. Both distances exceed the 2.3 $\mathrm{m}$ traveled at the casting speed over this time. As time increases, the strand eventually becomes filled with the new grade, as indicated by the general increase in B concentration with time.

Figure 6 presents the concentration history of a particular point in the strand $(6 \mathrm{~m}$ below the meniscus at the centerline). The relative concentration of element B stays at zero for 100-250 seconds, indicating a significant component of plug flow through the strand. Relative concentration then increases rapidly, before slowing down to gradually approach $100 \%$ (the new grade). This effect indicates the diffusion backmixing component of the flow. 
Figure 6 also shows the effect of "ramping" the casting speed according to Figure 2. The lower average velocity of steel in the strand increases the time to reach a given concentration. The curve predicted with ramping shows a time lag of about $120 \mathrm{~s}$ behind that predicted without ramping. This corresponds to the time difference between bulk movement in the two cases.

\section{Slab Composition}

Based on the predicted composition histories in the strand, the final composition distribution in the slab was calculated and investigated under the conditions in Table I. Figure 7 presents the isoconcentration contours on the surface of a quarter slab with a length of $12 \mathrm{~m}$ and Figure 8 shows corresponding results in transverse sections through the interior. Together, these figures show the dramatic differences in composition that arise both down the slab and between the slab surface and interior.

The slab surface, which is created at the meniscus, has relatively straight isoconcentration lines across the slab width. Before the transition, the surface composition is naturally $100 \%$ of the old grade, containing $0.0 \mathrm{~B}$. The composition then sharply changes at the "transition point", which corresponds to the part of the slab that was solidifying at the meniscus at the time the grade change began. This transition point is consistent with the "double pour point," which refers to the lines formed on the surface of the slab due to the casting speed changes. The transition point defines the origin $(0)$ in the $\mathrm{z}$ casting direction of the slab. The fraction of new grade increases rapidly after (above) this point and reaches $95 \%$ at the wide face surface by $-6 \mathrm{~m}$.

It is interesting to notice the slightly (3-10\%) higher composition at the narrow face than at the center of wide face near the transition point. This variation across the mold width is produced because the meniscus at the narrow face wall always meets new steel coming from the nozzle before the center line.

Mixing in the strand is very important to composition in the slab interior. Figures 7 and 8 show that the new grade reaches about $10 \%$ near the wide face center plane at $6 \mathrm{~m}$ below the transition point. This illustrates how deeply the new grade penetrates into the slab. Combined with mixing at the surface, a total of about $14 \mathrm{~m}$ of intermixed slab is

produced, based on a mixing criterion of between $5 \%$ and $95 \%$ new or old grades. The intermixing length at the surface is only $6 \mathrm{~m}$ using the same criterion. 
Comparing Figure 8 with Figure 5 shows how the combined effects of solidification and mixing make the composition profile developed in the slab very different from the distributions calculated in the strand. As the strand moves during casting, the composition becomes fixed upon solidification at the shell interface. The resulting isoconcentration lines in the slab are almost all parallel to the mold walls, perpendicular to the direction of growth of the columnar dendrites. At $6 \mathrm{~m}$ below the transition point, this composition distribution affects only the center region and might be mistaken for centerline segregation.

Figure 8 also predicts some interesting reversals in concentration gradient moving into the slab. These are due to solidification of regions where the fluid is moving upward in the opposite direction of the casting speed. The magnitude of the effect is not particularly significant.

These results show that intermixing is not uniform within the slab. The surface is intermixed only above the transition point. In contrast, the center line has much deeper intermixing below. This effect is seen more clearly in Figure 9, which presents the relative concentration of element $B$ down the slab at different depths beneath the surface. The surface longitudinal composition gradient is largest near the transition point and is generally greater than the gradients inside the slab. The concentration curves show long tails extending above the transition point at the surface and below the transition point at the center. The furthest extent of intermixing is found at the center of the slab below the transition point.

Based on Figure 9, the length of the intermixing region could be defined in several different ways, according to the mixing criterion and whether surface or interior is more important. Estimation of the intermixing length based solely on surface composition measurements would ignore a significant intermixing length in the center below the transition point.

The intermix length could alternatively be based on the average composition across the transverse section, which is presented in Figure 10. These results are naturally intermediate between those of the surface and centerline. The average intermixing distance is thereby shorter than that based on local compositions (Figure 9). It is shortened the most below the transition point because the slab is completely old grade in this region, except at the center. 


\section{MODEL VERIFICATION}

\section{A. Comparison between 1-D and 3-D Strand Models}

The results predicted by the simple 1-D model are compared with those of the 3-D model in several ways. Relative concentration results in the strand are compared for the region of $3 \mathrm{~m}$ to $6 \mathrm{~m}$ in Figure 6 . The velocity and concentration inlet conditions at the $3 \mathrm{~m}$ plane were taken from a separate $3-\mathrm{D}$ model run in both cases. It is seen that good agreement between both models has been achieved, indicating that 1-D diffusion (complete mixing across slab lateral sections) is a reasonable assumption after $3 \mathrm{~m}$. The greatest deviation occurs in the initial period when the concentration first increases above zero. The 1-D model slightly under-estimates mass transport at this time and correspondingly overestimates it later. These results imply that the 1-D model should be adequate lower in the strand (below $6 \mathrm{~m}$ ) where this assumption is even more reasonable.

In Figure 9, the 1-D model was run starting from the meniscus with a 15 times enhancement of diffusivity for the first $3 \mathrm{~m}$ top portion of the strand to account for the effect of 3-D flow and mixing. This extended 1-D model predicts the same concentrations in the slab centerline as the 3-D model. The 1-D model assumes a sudden jump from $\mathrm{C}_{0}=$ 0 to $\mathrm{C}_{0}=1$ at the transition point at the slab surface so is less accurate at predicting composition closer to the surface. This is also reflected in the crude prediction of average composition, which is indicated in Figure 10.

\section{B. Comparison between Strand Model and Analytical Solution}

The upwinding scheme used to develop the finite difference equations is known to cause potential numerical problems called "numerical diffusion" and "numerical dispersion." The latter problem is related to flow that is not parallel to any of the coordinate axes. Because flow in the strand is predominantly parallel to the casting direction, which is aligned with the $\mathrm{z}$ axis, attention was focused on the extent of false numerical diffusion in this direction.

To verify the accuracy of the transient mass transfer models in the strand and to investigate the influence of numerical diffusion, a 1-D analytical solution was found for Equations [8]-[13] for the special case of no diffusion, $\mathrm{D}_{\text {eff }}=0$. The solution is simply a 
transformation of a constant concentration profile from a Lagrangian system $\mathrm{C}(\mathrm{x}, \mathrm{y}, \tau)$ to the present Eulerian system $\mathrm{C}(\mathrm{x}, \mathrm{y}, \mathrm{z}, \mathrm{t})$. It can be written as:

$$
\begin{array}{ll}
\tau>0: & \mathrm{C}=\mathrm{C}_{1}(\mathrm{x}, \mathrm{y}, \tau) \\
\tau \leq 0: & \mathrm{C}= \begin{cases}0 & \text { for element } \mathrm{A} \\
1 & \text { for element } \mathrm{B}\end{cases}
\end{array}
$$

where $\mathrm{C}_{1}(\mathrm{x}, \mathrm{y}, \tau)$ is the $3-\mathrm{D}$ concentration solution at the distance, $\mathrm{Z}_{1}$, which is taken to be $3 \mathrm{~m}$ and as the inlet of the domain for this case. $\tau$ is the time needed for a point in the strand with position $\mathrm{z}$ to reach the distance, $\mathrm{Z}_{1}$, and is determined by:

$$
\tau=\mathrm{t}-\int_{\mathrm{Z}_{1}}^{\mathrm{Z}} \frac{\mathrm{dz}}{\mathrm{v}_{\mathrm{Z}}}
$$

Since $\mathrm{v}_{\mathrm{Z}}$ was assumed constant, equal to the casting speed, $\mathrm{V}_{\mathrm{c}}$ (without ramping), Equation [24] reduces to:

$$
\tau=\mathrm{t}-\frac{\mathrm{z}-\mathrm{Z}_{1}}{\mathrm{~V}_{\mathrm{c}}}
$$

A solution was obtained on a $16.6 \mathrm{~m}$ long domain starting from $\mathrm{Z}_{1}(3 \mathrm{~m})$ down the strand under conditions in Table I with constant casting speed. The inlet condition at $\mathrm{Z}_{1}$ was taken from time-dependent results from the 3-D model, as described before. The results are compared in Figure 11 with the predictions of the 1-D mass transfer model, run under the same conditions both with and without turbulent diffusion. The discrepancy between the analytical solution and the model run without diffusion is attributed to false numerical diffusion.

The results show that numerical diffusion in the casting direction below $3 \mathrm{~m}$ in the strand is much smaller than turbulent diffusion and thus has very little effect on the predictions. The greatest error arises in the initial stages of mixing, where the maximum effect of numerical diffusion reaches $30 \%$ of the turbulent diffusion results.

These results also indicate that turbulent eddy motion in the liquid pool greatly enhances mass transport, as it does transport of momentum and energy as well.

\section{Comparison between Slab Composition Predictions and Measurements}


The slab model predictions of relative concentration down the slab centerline are compared in Figures 12 and 13 with measurements performed by researchers at Inland Steel. ${ }^{[2]}$ The predicted compositions were determined using all three models, as described in sections II-IV. Casting conditions for both measurements and predictions are given in Table I. Overall agreement is good, as the same trends for both the predictions and the measurements can be seen in the figures.

Any difference in mixing behavior between different elements is due to differences in their molecular diffusivities in liquid steel, which are shown in Table III ${ }^{[21,22]}$ to range from $5 \times 10^{-9}$ to $5 \times 10^{-7} \mathrm{~m}^{2} / \mathrm{s}$. These values are at least three orders of magnitude smaller than the turbulent diffusivity of $6.7 \times 10^{-4} \mathrm{~m}^{2} / \mathrm{s}$ calculated with the data in Table I assuming the turbulent Schmidt number to be 1. Thus, diffusion is dominated by the turbulent component of diffusivity. Differences in the molecular diffusivities have almost no effect on diffusion.

Mixing behavior is controlled by mass convection, through the flow pattern, and turbulent mass diffusion. This is consistent with previous findings that momentum and heat transfer in the continuous caster are dominated by the turbulent viscosity and turbulent

conductivity respectively. ${ }^{[13]}$ Since different elements should be affected equally by turbulence, no difference is predicted between the relative concentrations of different elements in the intermixed slabs under the same casting conditions. Thus, only two numerical elements, A and B, were used in compiling Figures 12 and 13. This argument appears to be justified, since there are no significant differences between the data points measured for different elements in different trials.

\section{EFFECT OF CASTING CONDITIONS}

Having explored the characteristics of the model predictions and attempted to demonstrate their validity, the model was next applied to investigate the effect of important casting variables on the mixing in the strand and the slab. Conditions were based on Table I using the standard combination of three models unless otherwise mentioned.

\section{A. Steel Grade}

Changing the composition of the steel was assumed to affect only the following liquid properties: density, viscosity, and diffusivity. These variables have almost no effect on the results. This is because only changes in the laminar properties were investigated. 
Turbulence dominates both the flow (through the turbulent viscosity) and the mass transfer (through the turbulent diffusivity). Thus, changes of more than a factor of 4 in the molecular viscosity and one or two orders of magnitude in the molecular diffusivity have no observable effect on either the flow or the mass transfer. Further studies were not conducted because the turbulent properties of liquid metals are not known well enough to properly modify the parameters concerned with turbulence properties. It is strongly suspected that the effect of element type is always negligible, so all elements intermix about the same, as discussed before. The only possible exception is carbon, whose rapid diffusion in the solid state may make a slight difference that has been ignored in this work.

The models presented in this work are currently being modified to account for time variation in $\mathrm{C}_{0}$ due to mixing in the tundish. To minimize the intermixed steel generated, the results of this work could be used in conjunction with a grade-dependent criterion to determine the length of steel to be downgraded for the given casting conditions. The torch cut-off could be programmed to cut off exactly this length of slab for downgrading.

\section{B. Mold Dimensions}

The model was next run to investigate the effect of mold dimensions, including mold width and thickness, on mixing in the strand and slab. To maintain the same casting speed, the flow rate through the nozzle is lower into narrow or thinner slabs. The resulting lower velocities decrease turbulence in the mold cavity, which tends to reduce diffusion in the strand. Figure 14 compares the concentration produced along the slab centerline and surface for different mold widths and thicknesses. It is obvious that mold width has no significant effect on mass transfer and mixing behavior. The lower diffusivity in the narrow mold results in a slightly sharper concentration change along the slab centerline. In addition, the shorter path for the jet to reach the mold walls delivers new grade to the meniscus region sooner, producing a slightly sharper change in the slab surface composition. The effect of mold width is much more important when there is mixing in the tundish. In this case, wider molds exhibit shorter intermixing lengths, since the same amount of mixed liquid from the tundish is cast as a shorter slab. ${ }^{[6]}$

In contrast to the mold width, mold thickness (slab thickness) has a very significant effect on both the slab surface and centerline intermixing, as shown in Figure 14. The thinner mold produces a remarkably shortened intermixed slab, assuming the same cooling conditions and corresponding shell growth rate. The solidification time and the metallurgical length decrease quadratically with the reduction in mold thickness. This 
creates much less mixing along the slab centerline. Meanwhile, slightly enhanced upper recirculation and shortened needed turbulent diffusion distance due to decrease of the mold thickness reduce the time for new grade to reach the meniscus, lessening the intermixing distance at the slab surface.

\section{Casting Speed}

The important influence of casting speed on mixing in the slab and the strand can be inferred from its part in the convection terms in the model equations described in section II, III and IV. Casting speed has little qualitative effect on the flow pattern in the strand. The magnitudes of the velocities simply change proportionally. However, the casting speed has a significant effect on both mixing in the strand and solidification.

A slower casting speed increases the time needed to reach a given concentration in the strand, as described in section $\mathrm{V}$ and Figure 6. This greatly reduces the extent of mixing in the strand. At the same time, however, the slower speed of the shell also decreases the metallurgical length. This partly compensates the previous effect. The net effect on the slab of lowering the casting speed is to slightly shorten the intermixing length, as shown in Figure 15. Higher casting speeds produce longer intermixing lengths, particularly in the slab interior.

\section{Ramping of Casting Speed}

Slowing down and then gradually speeding up the casting speed during a grade change has an important effect on intermixing. The effect can be explained in terms of the overall slower casting speed involved with ramping, which increases the time needed to reach a given concentration in the strand. Thus, the longer the ramping time, (i.e. slower average casting speed), the shorter the intermixing length. The magnitude of this effect down the slab centerline is shown in Figure 16.

\section{E. Nozzle Design}

The effect of nozzle design was investigated by changing the angle and submergence depth of the incoming jet. The calculated effect of submergence depth is much smaller than the effect of jet angle. Standard conditions, which assume a jet angle of about $25^{\circ}$ down, correspond to the flow exiting a typical bifurcated nozzle with oversized

ports angled about $15^{\circ}$ downward. ${ }^{[12]}$ The extreme case of increasing the nozzle port angle 
to more than $30^{\circ}$ up to produce a $5^{\circ}$ downward jet ${ }^{[12]}$ is compared in Figure 17 with the standard case. The results indicate that changing nozzle design affects intermixing only at the slab surface, with almost no change in the slab interior.

Slab surface composition changes significantly when the nozzle design is changed. Decreasing the jet angle transports new grade to the meniscus faster, thereby reducing the extent of intermixing along the slab surface. There is no measurable change in mixing along the middle depth or centerline of the slab, however. This is because the change of flow pattern and mixing due to the nozzle design only affects the very upper portion of the strand. The effect decays very rapidly with distance from the meniscus, and almost completely disappears below about $3 \mathrm{~m}$ down the strand, where the solidified shell is only about $45 \mathrm{~mm}$ thick. Thus, internal mixing behavior below this depth is expected to be identical for the different nozzle designs, as observed in Figure 17. 


\section{CONCLUSIONS}

1. A mathematical model has been developed to calculate the mixing in the strand and the slab during steel grade transition in the continuous slab casting processes, based on turbulent 3-D fluid flow and mass transfer. The model calculations show good agreement with available experimental measurements for a simultaneous grade and tundish change.

2. Mixing in the strand is significant, affecting more than 25 tonnes steel and creating 12-14 m of intermixed slab under typical casting conditions (Table I). This is important, regardless of whether the tundish is changed at the time of the grade change or not.

3. The intermixing length depends mainly on the mold thickness (slab thickness) and is almost unaffected by the mold width for the conditions studied.

4. Significant increase of the casting speed produces slightly more intermixing in the slab. Higher speeds decrease the time needed to reach a given concentration in the strand. This is partially compensated by the simultaneous increase in the metallurgical length. Ramping the casting speed also has a slight effect on intermixing in the slab through its slowing down of the average casting speed.

5. Nozzle design changes, which influence the jet angle and submerged depth entering the mold cavity, slightly affect intermixing at the slab surface, but have no influence on intermixing in the slab interior.

6. Different elements were found to have the same mixing behavior under the same casting conditions, despite having different molecular properties. This is because the mass transport of solute due to turbulent eddy motion is many orders of magnitude larger than molecular diffusion and thus dominates the resulting composition distributions.

7. Numerical diffusion caused by finite difference schemes was confirmed to be much less important than turbulent diffusion. In the lower portion of the strand (e.g., 3 meters below the meniscus), the flow and diffusion can be reasonably approximated as 1-D. 


\section{APPENDIX I GOVERNING EQUATIONS FOR FLUID FLOW}

Volume Conservation Equation:

$$
\frac{\partial v_{x}}{\partial x}+\frac{\partial v_{y}}{\partial y}+\frac{\partial v_{z}}{\partial z}=0
$$

Momentum Conservation Equations:

$$
\begin{aligned}
& \rho\left(v_{x} \frac{\partial v_{x}}{\partial x}+v_{y} \frac{\partial v_{x}}{\partial y}+v_{z} \frac{\partial v_{x}}{\partial z}\right) \\
& =-\frac{\partial p}{\partial x}+\frac{\partial}{\partial x}\left(2 \mu_{e f f} \frac{\partial v_{x}}{\partial x}\right)+\frac{\partial}{\partial y}\left(\mu_{e f f}\left[\frac{\partial v_{x}}{\partial y}+\frac{\partial v_{y}}{\partial x}\right]\right)+\frac{\partial}{\partial z}\left(\mu_{e f f}\left[\frac{\partial v_{x}}{\partial z}+\frac{\partial v_{z}}{\partial x}\right]\right) \\
& \rho\left(v_{x} \frac{\partial v_{y}}{\partial x}+v_{y} \frac{\partial v_{y}}{\partial y}+v_{z} \frac{\partial v_{y}}{\partial z}\right) \\
& =-\frac{\partial p}{\partial y}+\frac{\partial}{\partial x}\left(\mu_{\text {eff }}\left[\frac{\partial v_{y}}{\partial x}+\frac{\partial v_{x}}{\partial y}\right]\right)+\frac{\partial}{\partial y}\left(2 \mu_{\text {eff }} \frac{\partial v_{y}}{\partial y}\right)+\frac{\partial}{\partial z}\left(\mu_{e f f}\left[\frac{\partial v_{y}}{\partial z}+\frac{\partial v_{z}}{\partial y}\right]\right) \\
& \rho\left(v_{x} \frac{\partial v_{z}}{\partial x}+v_{y} \frac{\partial v_{z}}{\partial y}+v_{z} \frac{\partial v_{z}}{\partial z}\right) \\
& =-\frac{\partial p}{\partial z}+\frac{\partial}{\partial x}\left(\mu_{\text {eff }}\left[\frac{\partial v_{z}}{\partial x}+\frac{\partial v_{x}}{\partial z}\right]\right)+\frac{\partial}{\partial y}\left(\mu_{\text {eff }}\left[\frac{\partial v_{z}}{\partial y}+\frac{\partial v_{y}}{\partial z}\right]\right)+\frac{\partial}{\partial z}\left(2 \mu_{\text {eff }} \partial v_{z}\right)+\rho f_{z}
\end{aligned}
$$

\section{Turbulence Equations}

$$
\begin{aligned}
& \rho\left(v_{x} \frac{\partial K}{\partial x}+v_{y} \frac{\partial K}{\partial y}+v_{z} \frac{\partial K}{\partial z}\right) \\
& =\frac{\partial}{\partial x}\left(\frac{\mu_{\text {eff }}}{\sigma_{K}} \frac{\partial K}{\partial x}\right)+\frac{\partial}{\partial y}\left(\frac{\mu_{\text {eff }}}{\sigma_{K}} \frac{\partial K}{\partial y}\right)+\frac{\partial}{\partial z}\left(\frac{\mu_{\text {eff }}}{\sigma_{K}} \frac{\partial K}{\partial z}\right)+\rho G_{K}-\rho \varepsilon \\
& \rho\left(v_{x} \frac{\partial \varepsilon}{\partial x}+v_{y} \frac{\partial \varepsilon}{\partial y}+v_{z} \frac{\partial \varepsilon}{\partial z}\right)
\end{aligned}
$$




$$
=\frac{\partial}{\partial x}\left(\frac{\mu_{\mathrm{eff}}}{\sigma_{\varepsilon}} \frac{\partial \varepsilon}{\partial \mathrm{x}}\right)+\frac{\partial}{\partial \mathrm{y}}\left(\frac{\mu_{\mathrm{eff}}}{\sigma_{\varepsilon}} \frac{\partial \varepsilon}{\partial \mathrm{y}}\right)+\frac{\partial}{\partial \mathrm{z}}\left(\frac{\mu_{\mathrm{eff}}}{\sigma_{\varepsilon}} \frac{\partial \varepsilon}{\partial z}\right)+\mathrm{c}_{1} \frac{\varepsilon}{\mathrm{K}} \rho \mathrm{G}_{\mathrm{K}}-\mathrm{c}_{2} \frac{\varepsilon}{\mathrm{K}} \rho \varepsilon
$$

where

$$
\begin{aligned}
\mu_{\text {eff }} & =\mu_{\mathrm{o}}+\mu_{\mathrm{t}}=\text { effective viscosity }\left(\mathrm{kg} \mathrm{m}^{-1} \mathrm{~s}^{-1}\right) \\
\mu_{\mathrm{t}} & =\mathrm{c}_{\mu} \rho \frac{\mathrm{K}^{2}}{\varepsilon}=\text { turbulent viscosity }\left(\mathrm{kg} \mathrm{m}^{-1} \mathrm{~s}^{-1}\right) \\
\mathrm{G}_{\mathrm{K}} & =\frac{\mu_{\mathrm{t}}}{\rho}\left[2\left(\frac{\partial \mathrm{v}_{\mathrm{x}}}{\partial \mathrm{x}}\right)^{2}+2\left(\frac{\partial \mathrm{v}_{\mathrm{y}}}{\partial \mathrm{y}}\right)^{2}+2\left(\frac{\partial \mathrm{v}_{\mathrm{z}}}{\partial \mathrm{z}}\right)^{2}+\left(\frac{\partial \mathrm{v}_{\mathrm{x}}}{\partial \mathrm{y}}+\frac{\partial \mathrm{v}_{\mathrm{y}}}{\partial \mathrm{x}}\right)^{2}+\left(\frac{\partial \mathrm{v}_{\mathrm{x}}}{\partial \mathrm{z}}+\frac{\partial \mathrm{v}_{\mathrm{z}}}{\partial \mathrm{x}}\right)^{2}+\left(\frac{\partial \mathrm{v}_{\mathrm{z}}}{\partial \mathrm{y}}+\frac{\partial \mathrm{v}_{\mathrm{y}}}{\partial \mathrm{z}}\right)^{2}\right] \\
& =\text { turbulence generation rate }\left(\mathrm{m}^{2} \mathrm{~s}^{-3}\right) \\
\mathrm{c}_{1} & =1.44, \quad \mathrm{c}_{2}=1.92, \quad \mathrm{c}_{\mu}=0.09, \quad \sigma_{\mathrm{K}}=1.0, \\
\mathrm{p} & =\quad \text { static pressure }(\text { Pa) } \\
\mathrm{v}_{\mathrm{i}} & =\quad \text { liquid velocity component in i direction }(\mathrm{i}=\mathrm{x}, \mathrm{y}, \text { or } \mathrm{z})\left(\mathrm{m} \mathrm{s}^{-1}\right) \\
\mathrm{z} & =\text { distance below meniscus (top surface) }(\mathrm{m}) \\
\mathrm{f}_{\mathrm{z}} & =\text { gravitational acceleration }=\mathrm{g}=9.81\left(\mathrm{~m} \mathrm{~s} \mathrm{~s}^{-2}\right)
\end{aligned}
$$

\section{APPENDIX II WALL LAW BOUNDARY CONDITIONS}

The following set of well-known wall function approximations are imposed on the near-wall grid nodes to account for the steep velocity gradients near a wall.

for $y_{+}>11.5$

$$
\begin{aligned}
& \tau_{\mathrm{w}}=\mathrm{v}_{\mathrm{t}}\left(\rho \mathrm{K}^{1 / 2} \mathrm{c}_{\mu} \kappa \frac{1}{\ln \left(\mathrm{Ey}_{+}\right)}\right) \\
& \mathrm{K}=\left(\mathrm{c}_{\mu}\right)^{-1 / 2} \frac{\kappa^{2} \mathrm{v}_{\mathrm{t}}^{2}}{\ln \left(\mathrm{Ey}_{+}\right)}
\end{aligned}
$$




$$
\varepsilon=\left(c_{\mu}\right)^{3 / 4} K^{3 / 2} \frac{\ln \left(E y_{+}\right)}{\kappa y_{n}}
$$

$$
\begin{aligned}
& \text { for } \mathrm{y}_{+} \leq 11.5 \\
& \begin{aligned}
\tau_{\mathrm{w}} & =\left(c_{\mu}\right)^{1 / 2} \rho \mathrm{K} \\
\mathrm{K} & =\left(\mathrm{c}_{\mu}\right)^{-1 / 2}\left(\frac{\mathrm{v}_{\mathrm{t}}^{2}}{\mathrm{y}_{+}^{2}}\right) \\
\varepsilon & =\left(\mathrm{c}_{\mu}\right)^{1 / 2} \mathrm{~K} \frac{\mathrm{v}_{\mathrm{t}}}{\mathrm{y}_{\mathrm{n}}} \\
\text { where } \mathrm{y}_{+} & =\left(\mathrm{c}_{\mu}\right)^{1 / 4} \frac{\rho \mathrm{y}_{\mathrm{n}}}{\mu_{\mathrm{o}}} \mathrm{K}^{1 / 2} \\
\mathrm{v}_{\mathrm{t}} & =\quad \text { liquid velocity component tangential to the wall }\left(\mathrm{m} \mathrm{s}^{-1}\right) \\
\tau_{\mathrm{w}} & =\text { shear stress at the wall }=\mu_{\mathrm{eff}} \frac{\partial \mathrm{v}_{\mathrm{t}}}{\partial \mathrm{n}}(\mathrm{Pa}) \\
\mathrm{n} & =\text { direction perpendicular to wall }
\end{aligned}
\end{aligned}
$$




\section{ACKNOWLEDGMENTS}

The authors wish to thank the steel companies: Inland Steel Corp. (East Chicago, IN), Armco Inc. (Middletown, OH), LTV Steel (Cleveland, OH) and BHP Co. Ltd. (Wallsend, Australia) for grants which made this research possible and for the provision of data. This work is also supported by the National Science Foundation under grant No. MSS-8957195. The authors are indebted to Inland Steel researchers, R. Gas and M. Monberg, for sharing their experimental measurements and data. Finally, thanks are due to Fluid Dynamics Inc. (Evanston, IL) for the use of FIPOST and to the National Center for Supercomputer Applications at the University of Illinois for time on the Cray 2 and CrayYMP supercomputers. 


\section{TABLE I SIMULATION CONDITIONS AND NOMENCLATURE}

Symbol Variable

C Relative concentration in strand

$\mathrm{C}_{\text {slab }} \quad$ Relative concentration in slab

$\mathrm{C}_{0} \quad$ Relative concentration at inlet (for 3-D modeling)

$\mathrm{C}_{1} \quad$ Relative concentration at $\mathrm{Z}_{1}$ below meniscus

$\mathrm{D}_{\text {eff }} \quad$ Effective diffusivity

$\mathrm{D}_{0} \quad$ Molecular diffusivity

E Wall roughness

$\mathrm{e}_{\mathrm{a}} \quad$ Allowable relative time truncation error

$\mathrm{e}_{\mathrm{n}} \quad$ Relative time truncation error at previous time step

$\mathrm{F} \quad$ Fraction of a given element

g Gravitational acceleration

$\mathrm{K} \quad$ Turbulent kinetic energy (inlet and initial values)

$\mathrm{k}_{\text {shell }} \quad$ Solidification constant in Eq. [19]

$\mathrm{L}_{\mathrm{h}} \quad$ Inlet height

$\mathrm{L}_{\mathrm{W}} \quad$ Inlet width

$\mathrm{L}_{\mathrm{m}} \quad$ Working mold length

$\mathrm{L}_{\mathrm{n}} \quad$ Nozzle submergence depth

$\mathrm{N} \quad$ Slab mold thickness (across narrow face)

$\mathrm{n} \quad$ Normal direction of boundaries

$\mathrm{p} \quad$ Static pressure (relative to outlet plane)

Re Reynolds number

$$
\begin{aligned}
& \text { inlet }\left(\mathrm{v}_{\mathrm{x} 0} \sqrt{\mathrm{L}_{\mathrm{h}} \mathrm{L}_{\mathrm{w}}} \rho \mu_{\mathrm{o}}{ }^{-1}\right) \\
& \text { outlet }\left(\mathrm{V}_{\mathrm{z}} \sqrt{\mathrm{NW}} \rho \mu_{\mathrm{o}}{ }^{-1}\right)
\end{aligned}
$$

$\mathrm{Sc}_{\mathrm{t}} \quad$ Turbulent Schmidt number

t

$\mathrm{t}_{\mathrm{S}} \quad$ Solidification time

$\mathrm{V}_{\mathrm{c}} \quad$ Casting speed

$\mathrm{V}_{\mathrm{cmin}} \quad$ Minimum casting speed during ramping

$\mathrm{v}_{\text {diff }}$ Diffusion velocity component in casting direction

$\mathrm{v}_{\mathrm{X}} \quad$ Velocity component in $\mathrm{x}$ direction

$\mathrm{v}_{\mathrm{X} 0} \quad$ Normal velocity through inlet (peak value)
See Eq. [1]

See Eq. [14]

See Eq. [5]

See Eq. [11]

See Eq. [3]

See Eq. [3]

0.8

0.001

See Eq. [7]

See Eq. [2]

$9.8 \mathrm{~m} \mathrm{~s}^{-2}$

$0.0502 \mathrm{~m}^{2} \mathrm{~s}^{-2}$

$0.00327 \mathrm{~m} \mathrm{~s}^{-0.5}$

$38 \mathrm{~mm}$

$60 \mathrm{~mm}$

$0.6 \mathrm{~m}$

$0.265 \mathrm{~m}$

$0.22 \mathrm{~m}$

See Eq. [6]

65,000

11,400

1

See Eq. [17] \& [19]

$0.0167 \mathrm{~m} \mathrm{~s}^{-1}$ (39 in $\left.\mathrm{min}^{-1}\right)$

$0.00334 \mathrm{~m} \mathrm{~s}^{-1}\left(7.8\right.$ in $\left.\mathrm{min}^{-1}\right)$

See Eq. [1]

$1.062 \mathrm{~m} \mathrm{~s}^{-1}$ 


$\begin{array}{lll}\mathrm{v}_{\mathrm{y}} & \text { Velocity component in y direction } & \text { See Eq. [1] } \\ \mathrm{v}_{\mathrm{y} 0} & \text { Horizontal velocity through inlet plane } & 0.0 \mathrm{~m} \mathrm{~s}^{-1} \\ \mathrm{v}_{\mathrm{z}} & \text { Velocity component in } \mathrm{z} \text { direction } & \text { See Eq. [1] } \\ \mathrm{v}_{\mathrm{z} 0} & \text { Downward velocity through inlet } & 0.471 \mathrm{~m} \mathrm{~s}^{-1}\end{array}$

$\mathrm{v}_{\mathrm{Zl}} \quad$ Velocity at $\mathrm{Z}_{1}$ below meniscus

See Eq. [9]

W Slab mold width

$1.32 \mathrm{~m}$ (52 in)

$\mathrm{x} \quad$ Coordinate in strand (mold width direction)

See Figure 3

$\mathrm{x}_{\mathrm{s}} \quad$ Coordinate in slab (slab width direction)

See Figures $7 \& 8$

y Coordinate in strand (mold thickness direction)

See Figure 3

$\mathrm{y}_{\mathrm{s}} \quad$ Coordinate in slab (slab thickness direction)

See Figures $7 \& 8$

$\mathrm{y}_{\mathrm{n}} \quad$ distance of near-wall node from wall

7 to $9 \mathrm{~mm}$

$Z_{\text {final }} \quad$ Metallurgical Length

$19.6 \mathrm{~m}$

$\mathrm{Z}_{1} \quad$ Strand length simulated by 3-D model, where

switching from 3-D model to 1-D model

$6 \mathrm{~m}$

$\mathrm{z} \quad$ Coordinate in strand (casting direction)

See Figures $1 \& 3$

$\mathrm{z}_{\mathrm{S}} \quad$ Coordinate in slab (distance from transition point)

See Figures $7 \& 8$

$\Delta \mathrm{L} \quad$ Shell thickness

See Eq. [19] \& [20]

$(\Delta \mathrm{t})_{\mathrm{n}} \quad$ Time increment at last time step

See Eq. [7]

$(\Delta t)_{n+1} \quad$ Time increment at this time step

See Eq. [7]

$\varepsilon \quad$ Dissipation rate (inlet and initial values)

$0.394 \mathrm{~m}^{2} \mathrm{~s}^{-3}$

$\kappa \quad$ Von Karmen constant

0.4

$\mu_{\text {eff }} \quad$ Effective viscosity (liquid steel at inlet)

$3.490 \mathrm{~kg} \mathrm{~m}^{-1} \mathrm{~s}^{-1}$

$\mu_{\mathrm{o}} \quad$ Laminar (molecular) viscosity

$0.00555 \mathrm{~kg} \mathrm{~m}^{-1} \mathrm{~s}^{-1}$

$\mu_{\mathrm{t}} \quad$ Turbulent viscosity (liquid steel at inlet)

$3.484 \mathrm{~kg} \mathrm{~m}^{-1} \mathrm{~s}^{-1}$

$\rho \quad$ Density (liquid steel)

$7020 \mathrm{~kg} \mathrm{~m}^{-3}$

$\tau \quad$ Combined time

See Eq. [24] \& [25] 
TABLE II CASTING CONDITIONS IN PLANT ${ }^{\text {[2] }}$

\begin{tabular}{cccccc}
\hline Trial & $\begin{array}{c}\text { Mold Width } \\
(\mathrm{m})\end{array}$ & $\begin{array}{c}\text { Minimum } \\
\text { Casing Speed } \\
\mathrm{V}_{\mathrm{cmin}}(\mathrm{m} / \mathrm{s})\end{array}$ & $\begin{array}{c}\text { Normal } \\
\text { Casting Speed } \\
\mathrm{V}_{\mathrm{c}}(\mathrm{m} / \mathrm{s})\end{array}$ & $\begin{array}{c}\text { Ramping } \\
\text { Time } \\
(\mathrm{s})\end{array}$ & $\begin{array}{c}\text { Distance Traveled } \\
\text { during ramping } \\
(\mathrm{m})\end{array}$ \\
\hline 1 & & 0.00334 & 0.0167 & 210 & 2.077 \\
2 & 1.293 & 0.00334 & 0.0167 & 240 & 2.378 \\
3 & 0.986 & 0.00334 & 0.0169 & 288 & 2.925 \\
4 & 0.842 & 0.00334 & 0.0167 & 288 & 2.909 \\
\hline
\end{tabular}

TABLE III MOLECULAR DIFFUSIVITY ${ }^{[21,22]}$

\begin{tabular}{ccc}
\hline Element & Diffusivity $\left(\mathrm{m}^{2} / \mathrm{s}\right)$ & $\begin{array}{c}\text { Concentration Range and } \\
\text { Temperature }\end{array}$ \\
\hline $\mathrm{Mn}$ & $4.6 \times 10^{-7}$ & $0-10 \%, 1550-1700{ }^{\circ} \mathrm{C}$ \\
& $4.37 \times 10^{-9}$ & $0-5.4 \%, 1550{ }^{\circ} \mathrm{C}$ \\
$\mathrm{Si}$ & $5.1 \times 10^{-8}$ & $0-4.4 \%, 1550-1725{ }^{\circ} \mathrm{C}$ \\
& $7.9 \times 10^{-9}$ & $0.03 \%, 1550{ }^{\circ} \mathrm{C}$ \\
$\mathrm{C}$ & $5.9 \times 10^{-9}$ & $2.1 \%, 1550{ }^{\circ} \mathrm{C}$ \\
& $4.3 \times 10^{-8}$ & $2.5 \%, 1500{ }^{\circ} \mathrm{C}$ \\
& $4.4 \times 10^{-7}$ & $0.05 \%, 1564{ }^{\circ} \mathrm{C}$ \\
\hline
\end{tabular}

TABLE IV TURBULENT PROPERTIES AT INLET ${ }^{[12]}$

\begin{tabular}{cccc}
\hline \multicolumn{2}{c}{$\begin{array}{c}\text { Casting Speed, } \mathrm{V}_{\mathrm{c}} \\
(\mathrm{m} / \mathrm{s})\end{array}$} & $\begin{array}{c}\text { Turbulent Kinetic Energy, K } \\
\left(\mathrm{m}^{2} / \mathrm{s}^{2}\right)\end{array}$ & $\begin{array}{c}\text { Dissipation Rate, } \varepsilon \\
\left(\mathrm{m}^{2} / \mathrm{s}^{3}\right)\end{array}$ \\
\hline 0.0084 & $(20)$ & 0.0212 & 0.0839 \\
0.0167 & $(39)$ & 0.0502 & 0.3935 \\
0.0250 & $(59)$ & 0.0850 & 1.0920 \\
0.0334 & $(78)$ & 0.1282 & 2.2932 \\
\hline
\end{tabular}




\section{REFERENCES}

1. H. Tanaka, S. Shiraishi, Y. Iwanaga, S. Hiwasa, K. Orito and A. Ichihara: "Automatization of Manual Operation in the Continuous Casting Process", Steel Technical Report, 1987, (17), pp. 18-25.

2. R. Gas and M. Monberg: Inland Steel, Inc., private communication, 1992.

3. R. Sussman and J. Schade: Armco Inc., private communication, 1992.

4. R. Mahapatra: BHP Co. Ltd., private communication, 1992.

5. M.L. Lowry and Y. Sahai: "Modeling of Thermal Effects in Liquid Steel Flow in Tundishes", 74th Steelmaking Conference, The Iron and Steel Society, Inc., 1991, Vol. 74, pp. 505-511.

6. M. T.. Burns, J. Schade, W.A. Brown and K.R. Minor: "Transition Model for Armco Steel's Ashland Slab Caster", Process Technology Conference (75th Steelmaking Conference), L.G. Kuhn, eds., The Iron and Steel Society, Toronto, Ontario, Canada, April 5-8, 1992, Vol. 10, pp. 177-186.

7. F.J. Mannion, A. Vassilicos and J.H. Gallenstein: "Prediction of Intermix Slab Composition at Cary No. 2 Caster", 75th Steelmaking Conference, L. G. Kuhn, eds., The Iron and Steel Society, Toronto, Ontario, Canada, April 5-8, 1992.

8. M.C. Tsai and M.J. Green: "Three Dimensional Concurrent Numerical Simulation of Molten Steel Behavior and Chemical Transition at Inland Steel' s No. 2 Caster Tundish", 74th Steelmaking Conference, The Iron and Steel Society, Inc., 1991, Vol. 74, pp. 501-504.

9. S. Joo and R.I.L. Guthrie: Int. Symp. on Ladle and Furnaces, CIM, Montreal, Canada, 1988, pp. 1-28.

10. O.J. Ilegbusi and J. Szekely: "The Modeling of Fluid Flow, Tracer Dispersion and Inclusion Behavior in Tundishes", Mathematical Modeling of Materials Processing Operations, J. Szekely, eds., Metallurgical Society, Inc., 1987, pp. 409. 
11. Y. Sahai: "Computer Simulation of Melt Flow Control Due to Baffles with Hole in Continuous Casting Tundishes", Mathematical Modeling of Materials Processing Operations, J. Szekely, eds., Metallurgical Society, Inc., 1987, pp. 431.

12. B.G. Thomas, L.M. Mika and F.M. Najjar: "Simulation of Fluid Flow and Heat Transfer Inside a Continuous Slab Casting Machine", Metallurgical Transactions, 1990, vol. 21B, pp. 387-400.

13. X. Huang, B.G. Thomas and F.M. Najjar: "Modeling Superheat Removal during Continuous Casting of Steel Slabs", Metallurgical Transactions B, 1992, vol. 23B, pp. 339-356.

14. B.E. Launder and B.I. Sharma: "Application of the Energy-Dissipation Model of Turbulence to the Calculation of Flow Near a Spinning Disc", Letters in Heat and Mass Transfer, 1974, vol. 1, pp. 131-138.

15. L.D. Smoot and P.J. Smith: Coal Combustion and Gasification, Plenum Press, 1985.

16. D.E. Hershey: Turbulent Flow of Molten Steel through Submerged Bifurcated Nozzles in the Continuous Casting Process, M. S. Thesis, University of Illinois at Urbana-Champaign, 1992.

17. B.G. Thomas and F.M. Najjar: "Finite-Element Modeling of Turbulent Fluid Flow and Heat Transfer in Continuous Casting", Applied Mathematical Modeling, 1991, vol. 15 , pp. 226-243.

18. E.B. Wylie and V.L. Streeter: Fluid Transients, McGraw-Hill International Book Company, 1978.

19. X. Huang: Studies on Turbulent Gas-Particle Jets and 3-D Turbulent Recirculating Gas-Particle Flows, Ph.D. Thesis, Tsinghua University, 1988.

20. S.V. Patankar: Numerical Heat Transfer and Fluid Flow, McGraw-Hill, 1980. 
21. K. Nagata, Y. Ono, T. Ejima and T. Yamamura: Handbook of Physico-Chemical Properties at High Temperatures (Chapter 7: Diffusion), K. Awai and Y. Shiraishi, eds., The Iron and Steel Institute of Japan, 1988, pp. 181-204.

22. L. Yang and G. Derde: "General Considerations of Diffusion in Melts of Metallurgical Interest", Physical Chemistry of Process Metallurgy - Part 1, G.R.S. Pierre, eds., Interscience Publishers, 1961, pp. 503-521. 


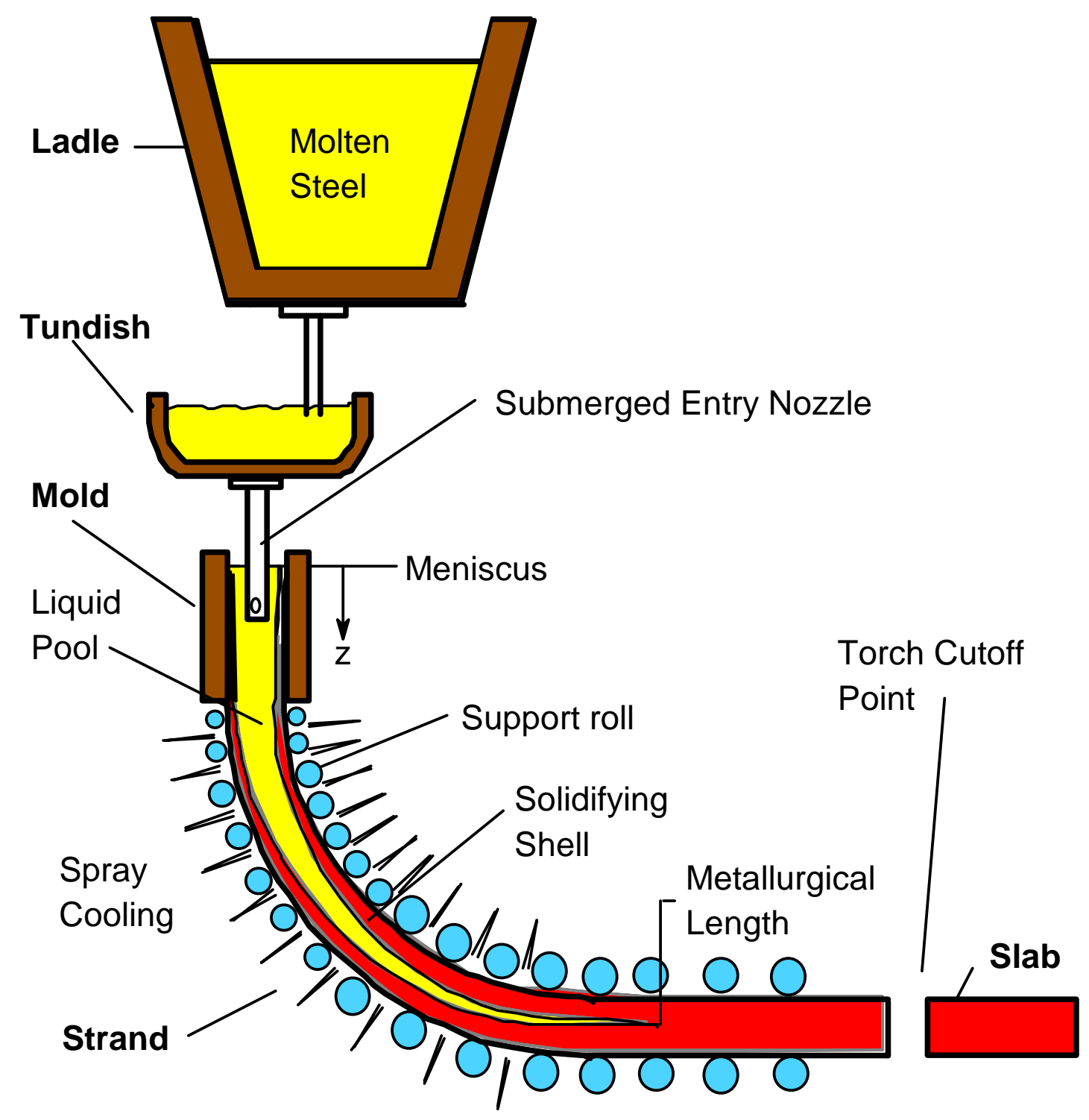

FIG. 1. Diagram of the continuous casting process. 
Time (min)

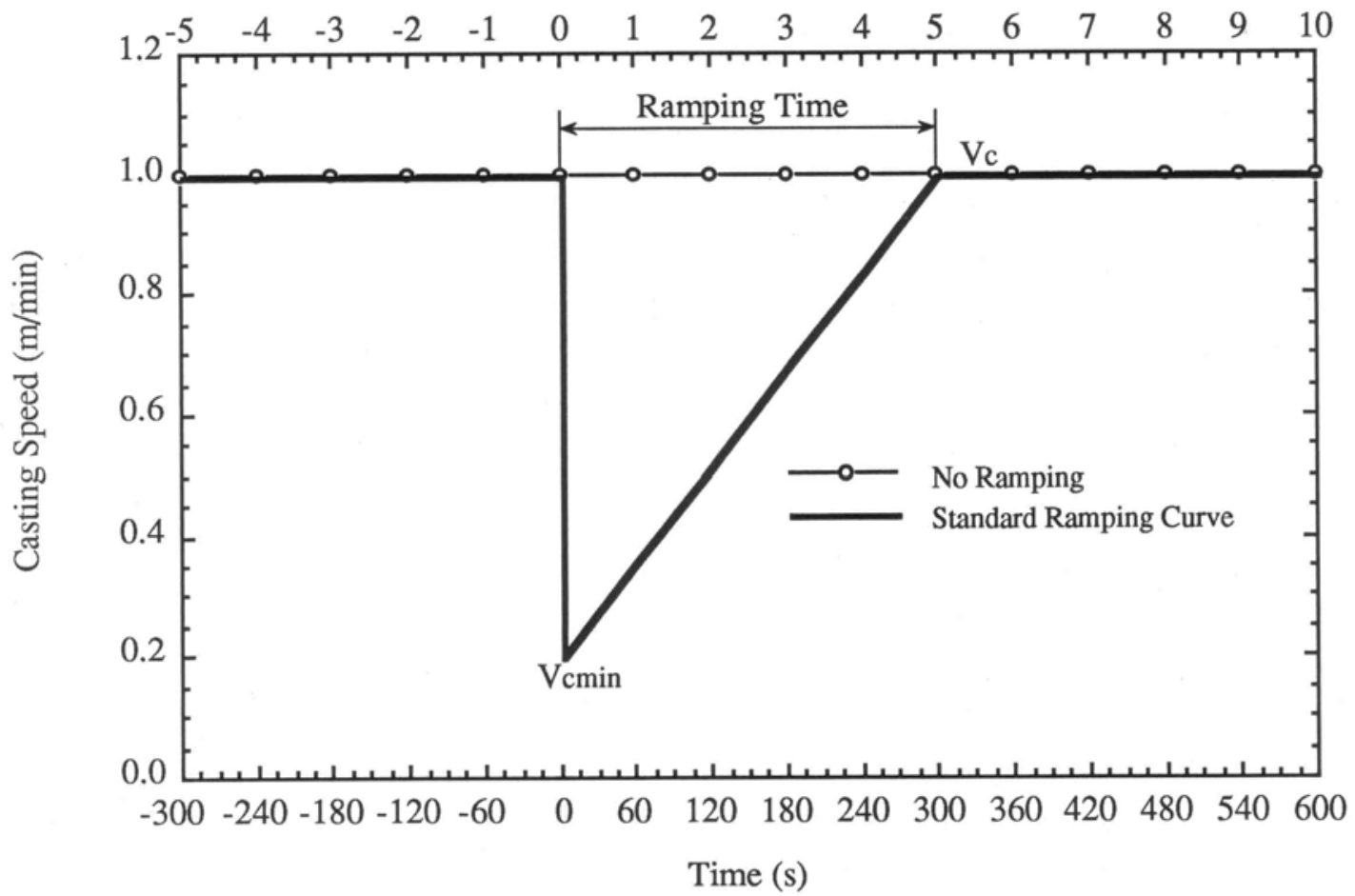

FIG. 2. Ramping of casting speed with time. 


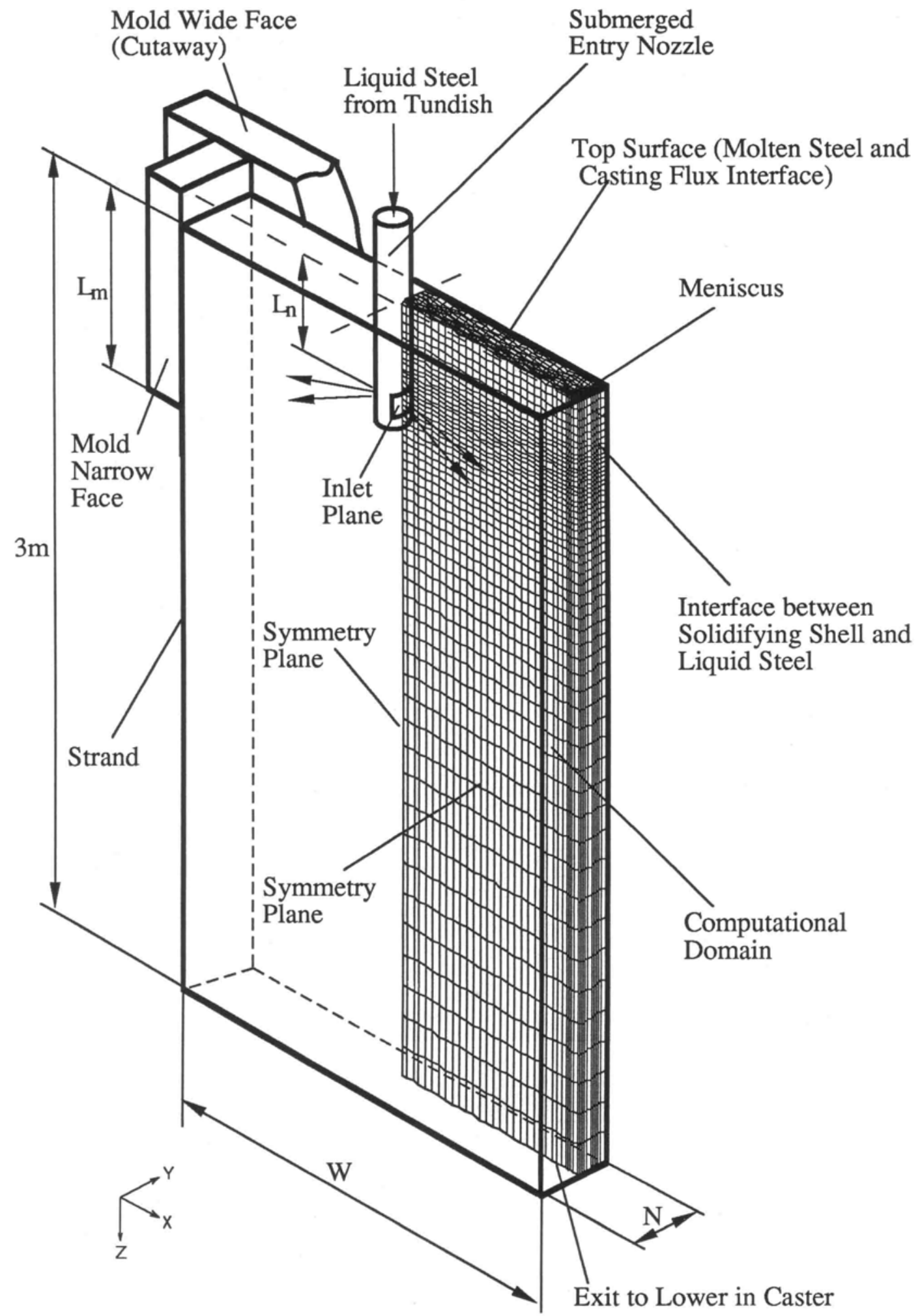

FIG. 3. Simulation domain and typical mesh used in 3D model. 


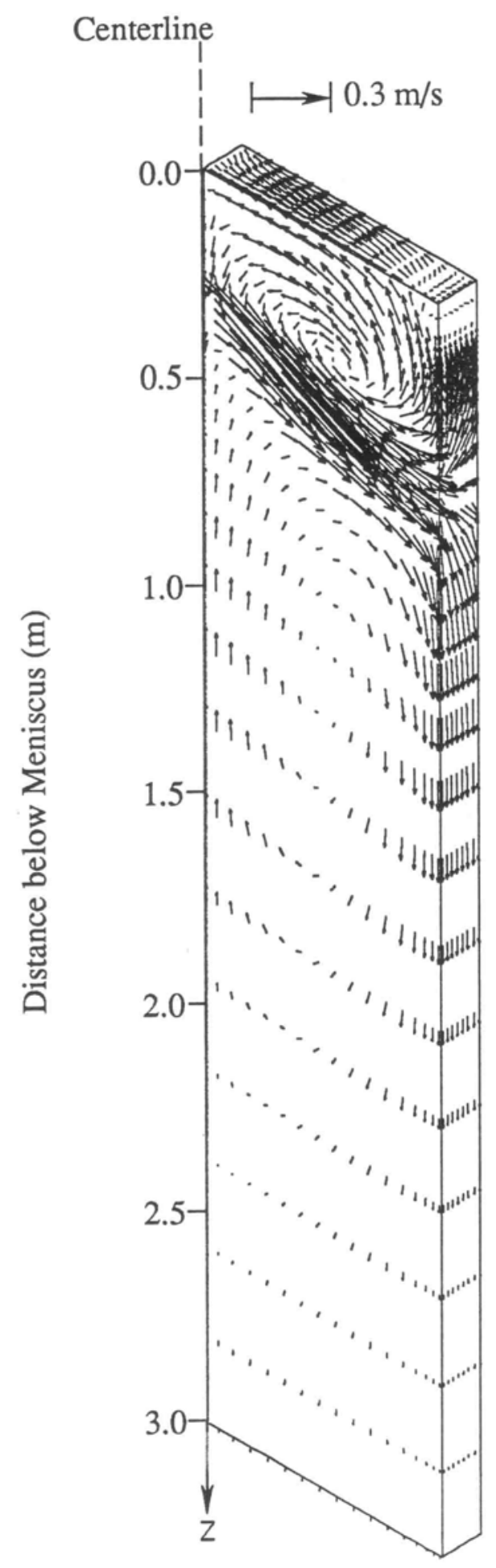

FIG. 4. Predicted flow pattern in first $3 \mathrm{~m}$ portion of strand. 


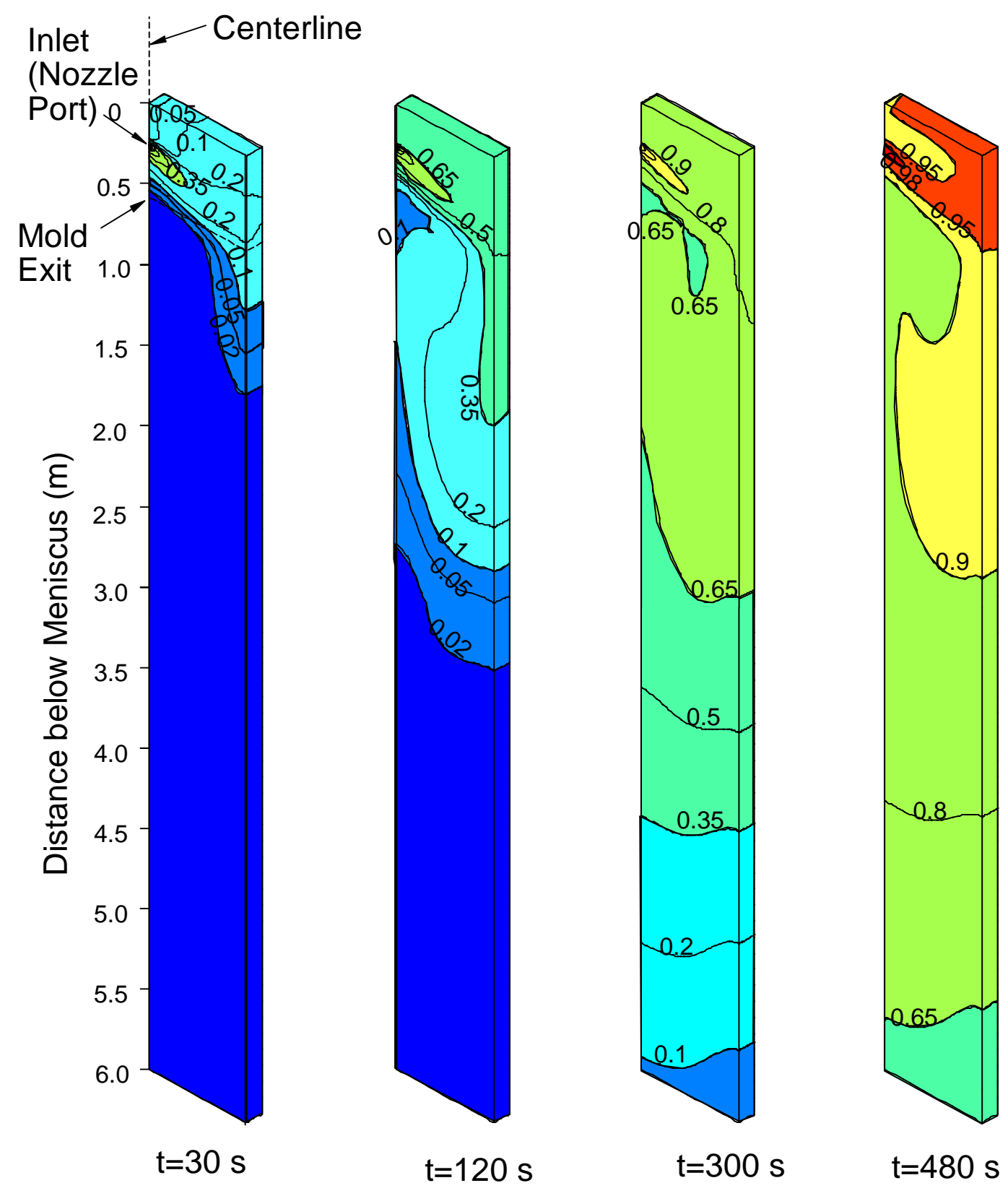

FIG. 5. Relative concentration of element B in strand 


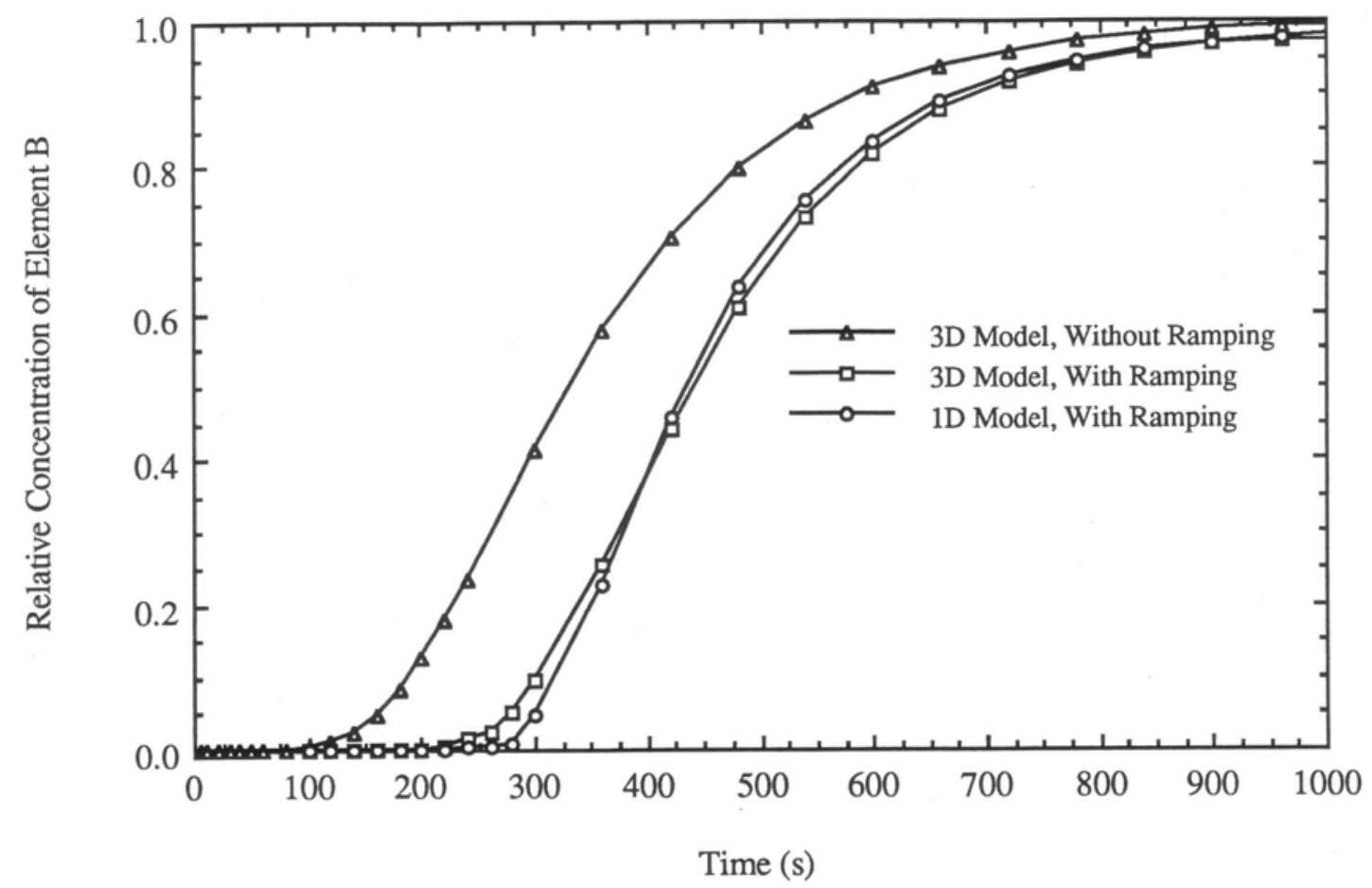

FIG. 6. History of relative concentration of elelment B (at center line of strand, $6 \mathrm{~m}$ blow meniscus).

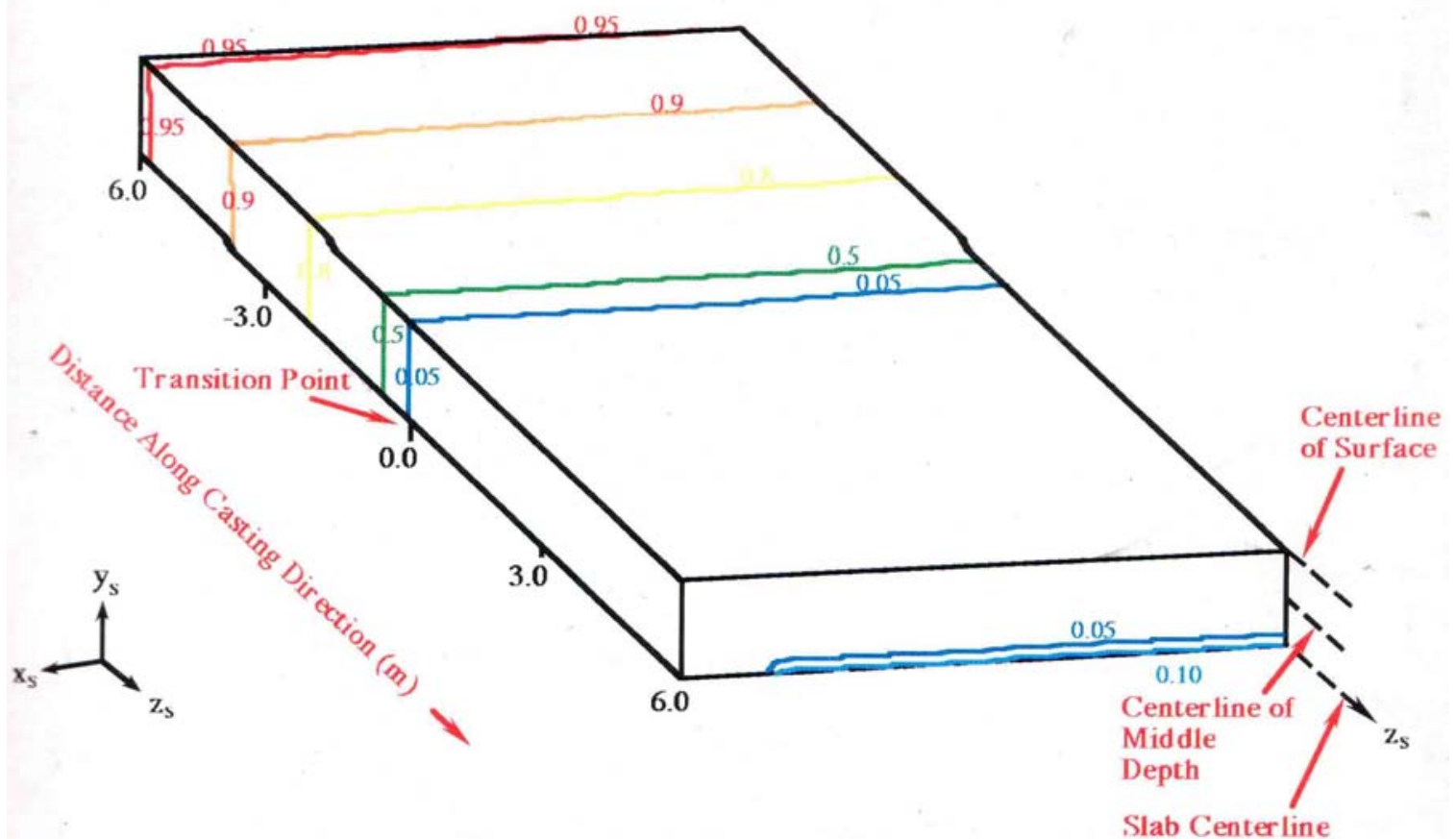

FIG. 7. Relative concentration of element $B$ at slab surface. 


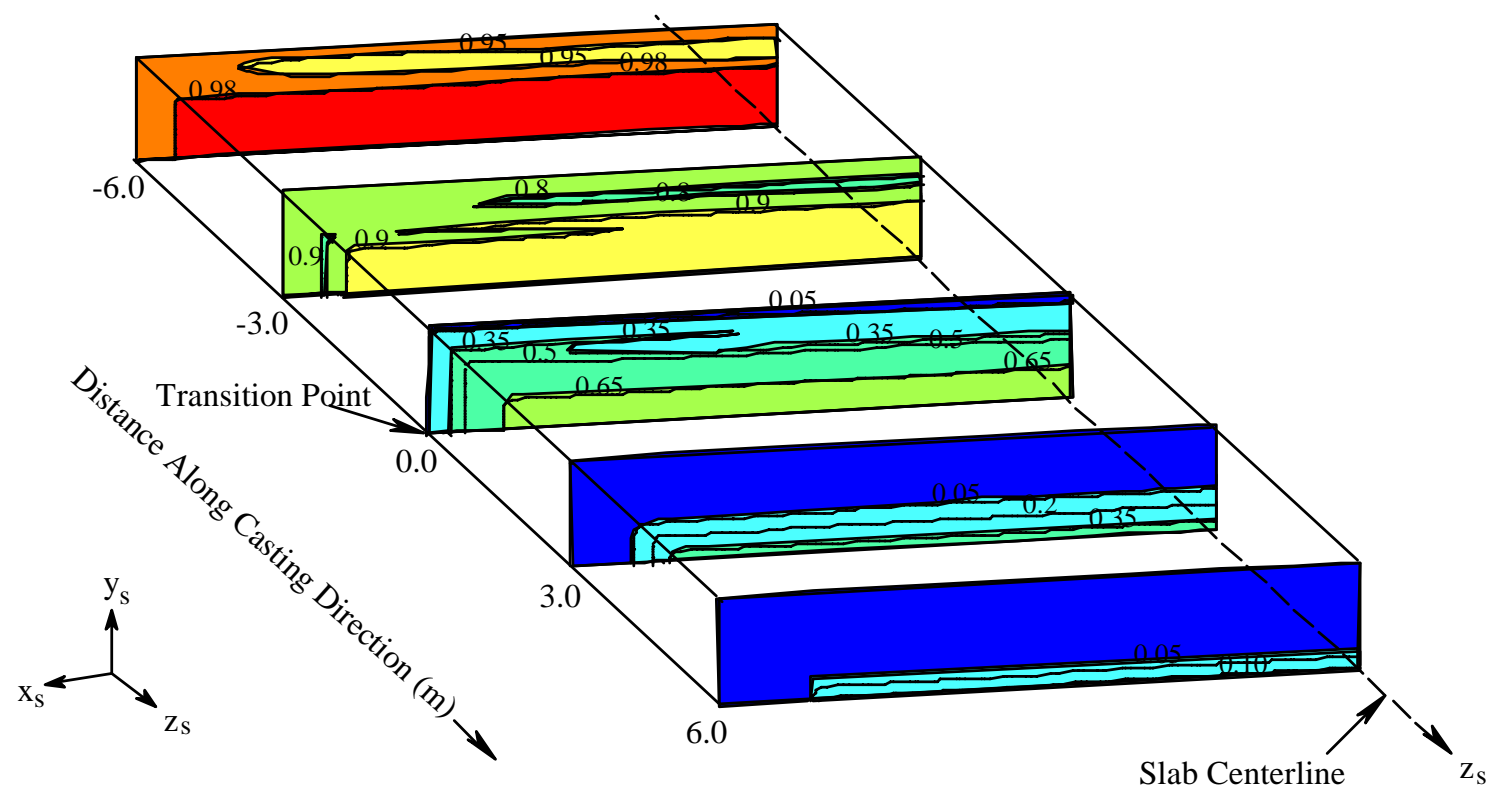

FIG. 8 Relative concentration of element B inside slab

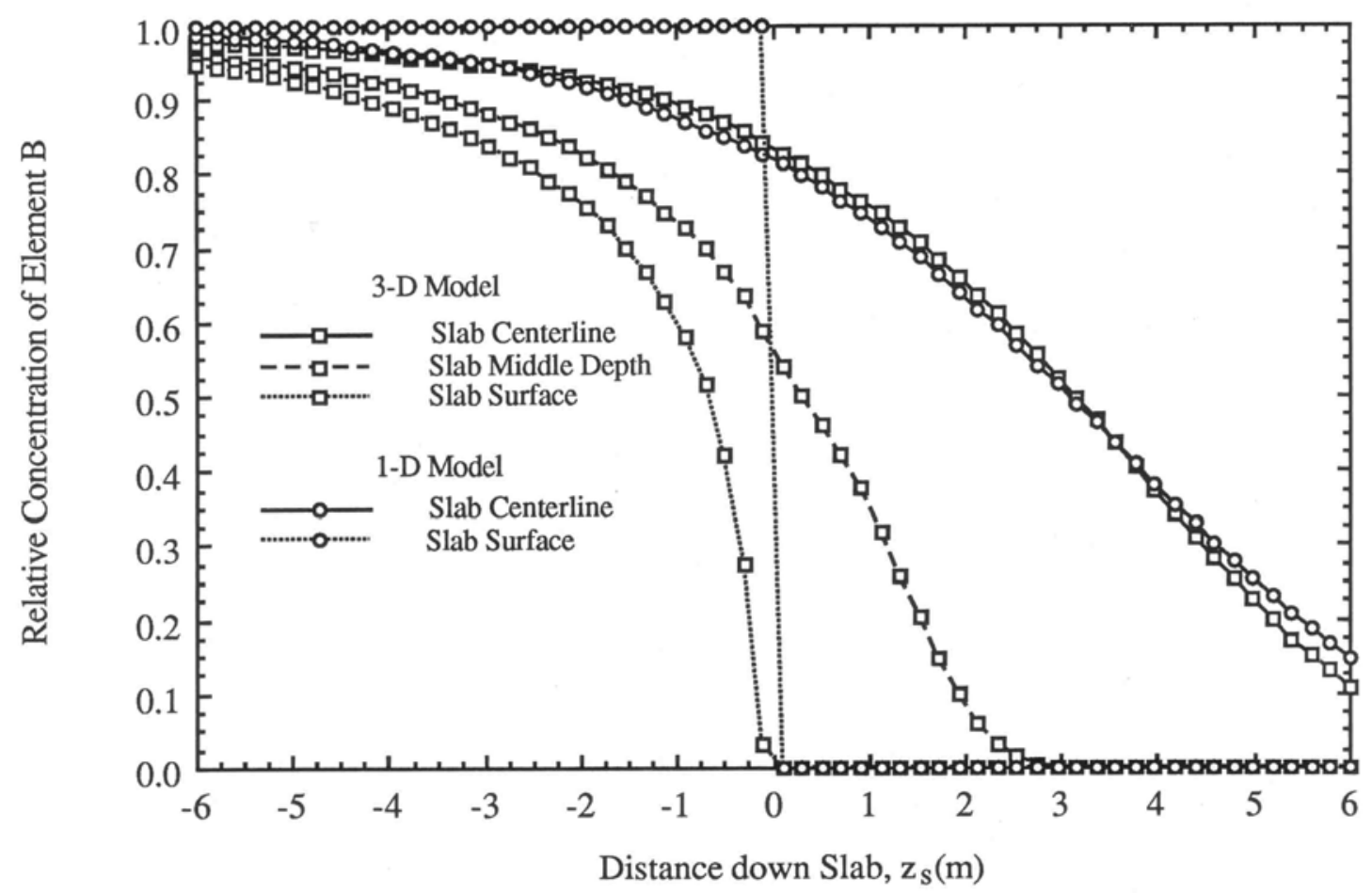

FIG. 9. Distribution of element B along centerlines at different depths beneath slab surface. 


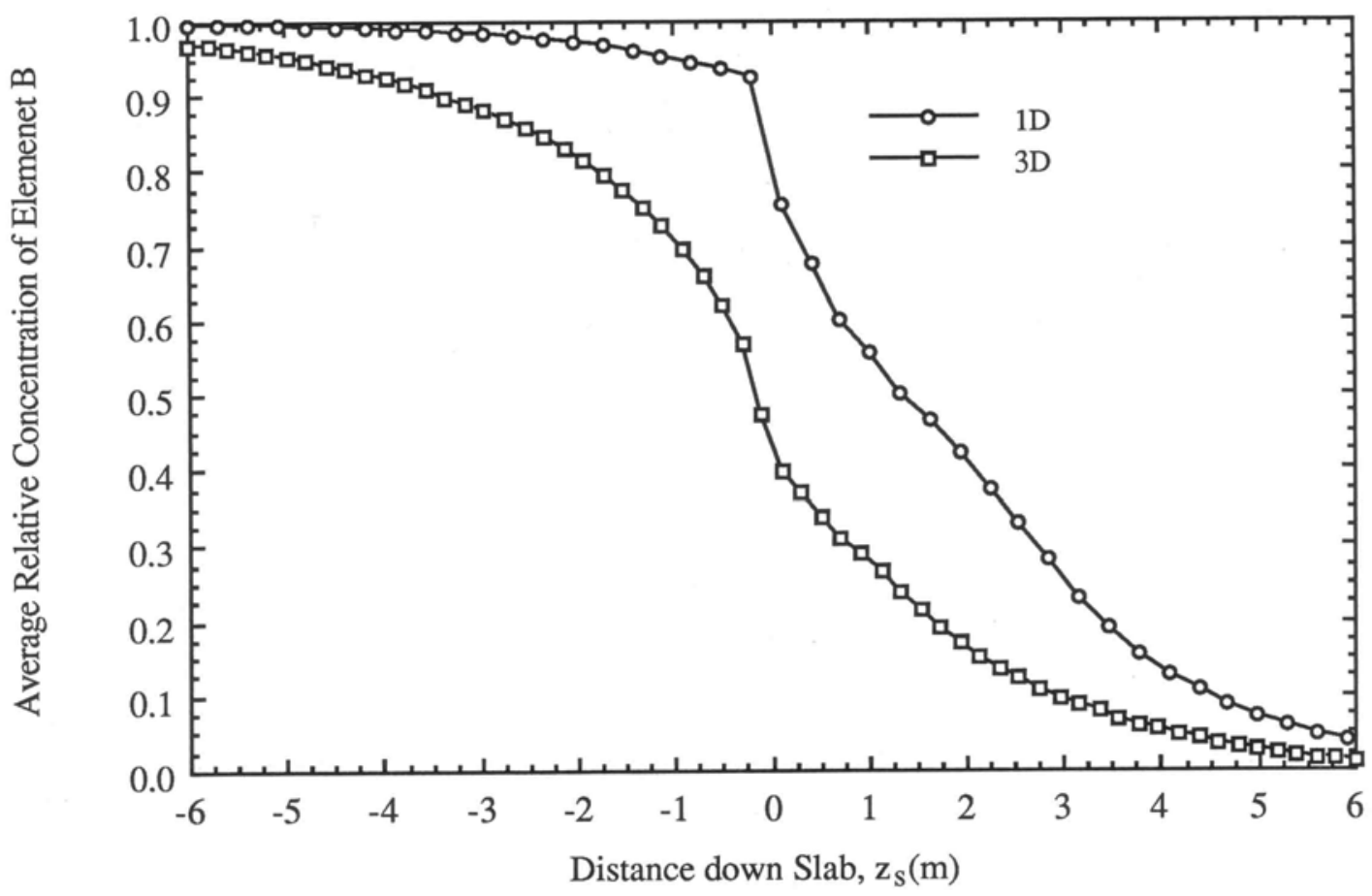

FIG. 10 Average concentration of element B along slab.

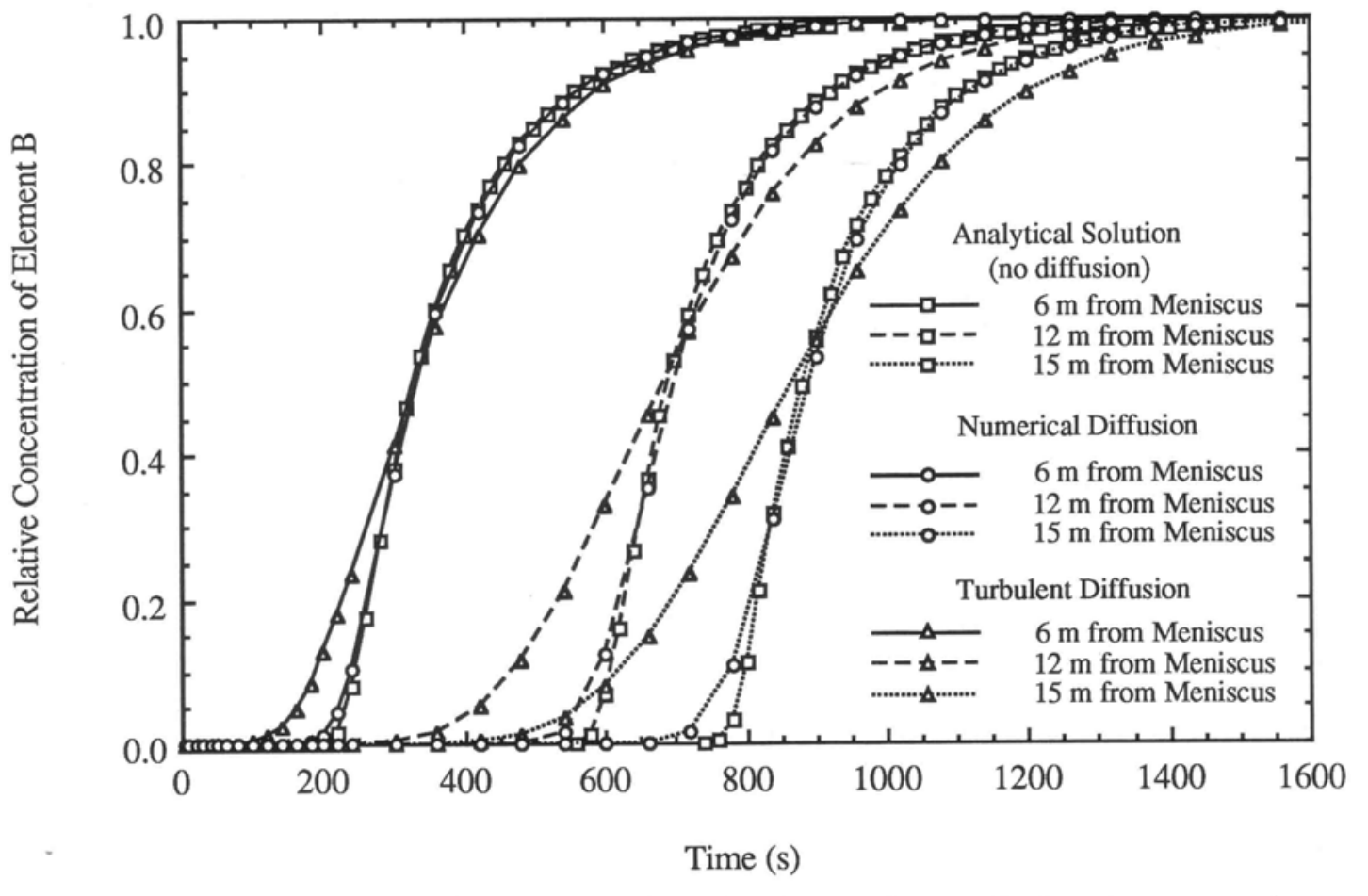

FIG. 11. Comparison between analytical and numerical prediction of concentration histories at specified points along strand centerline. 


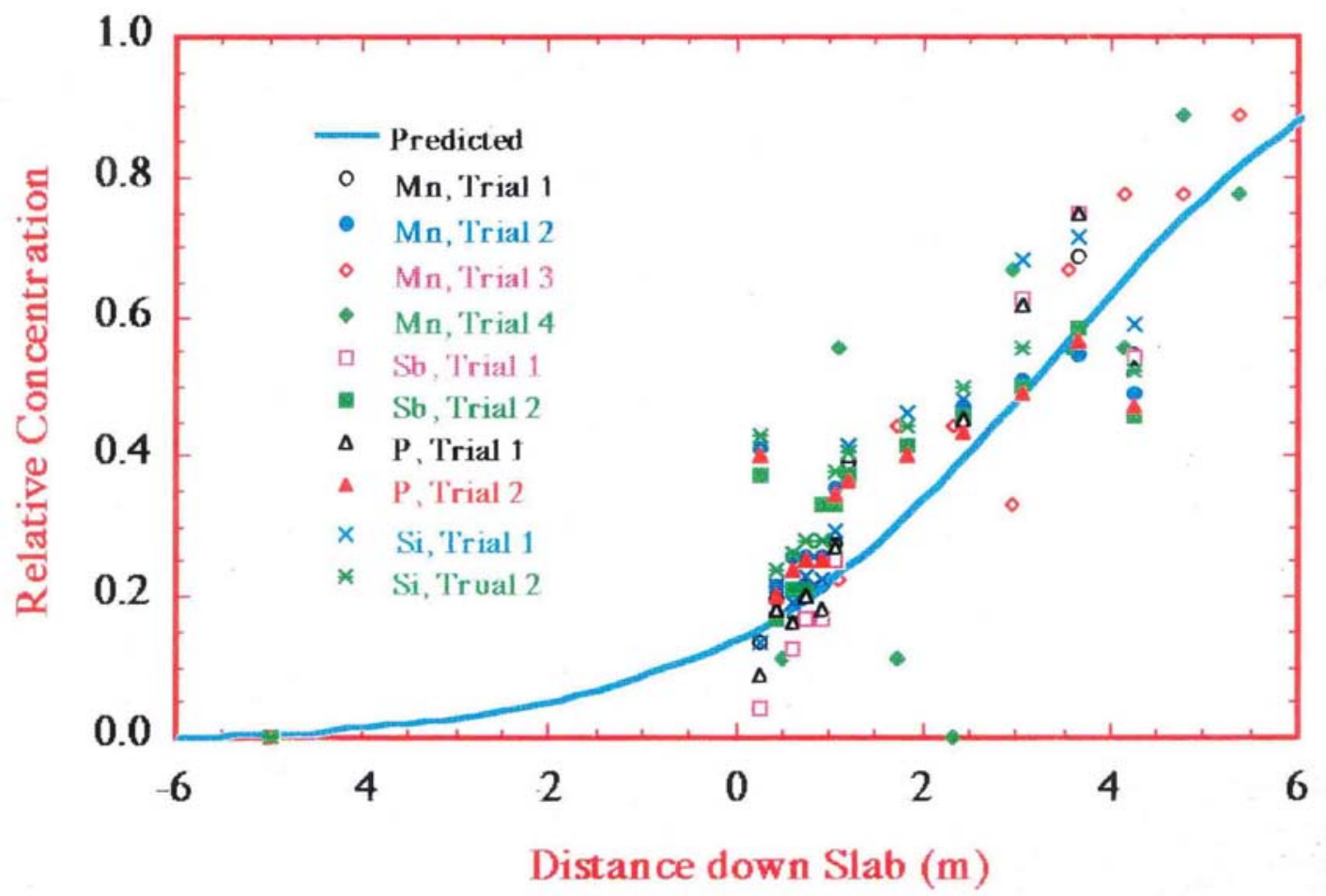

FIG. 12. Comparison between predicted and measured ${ }^{[2]}$ relative concentration of element A along slab centerline. 


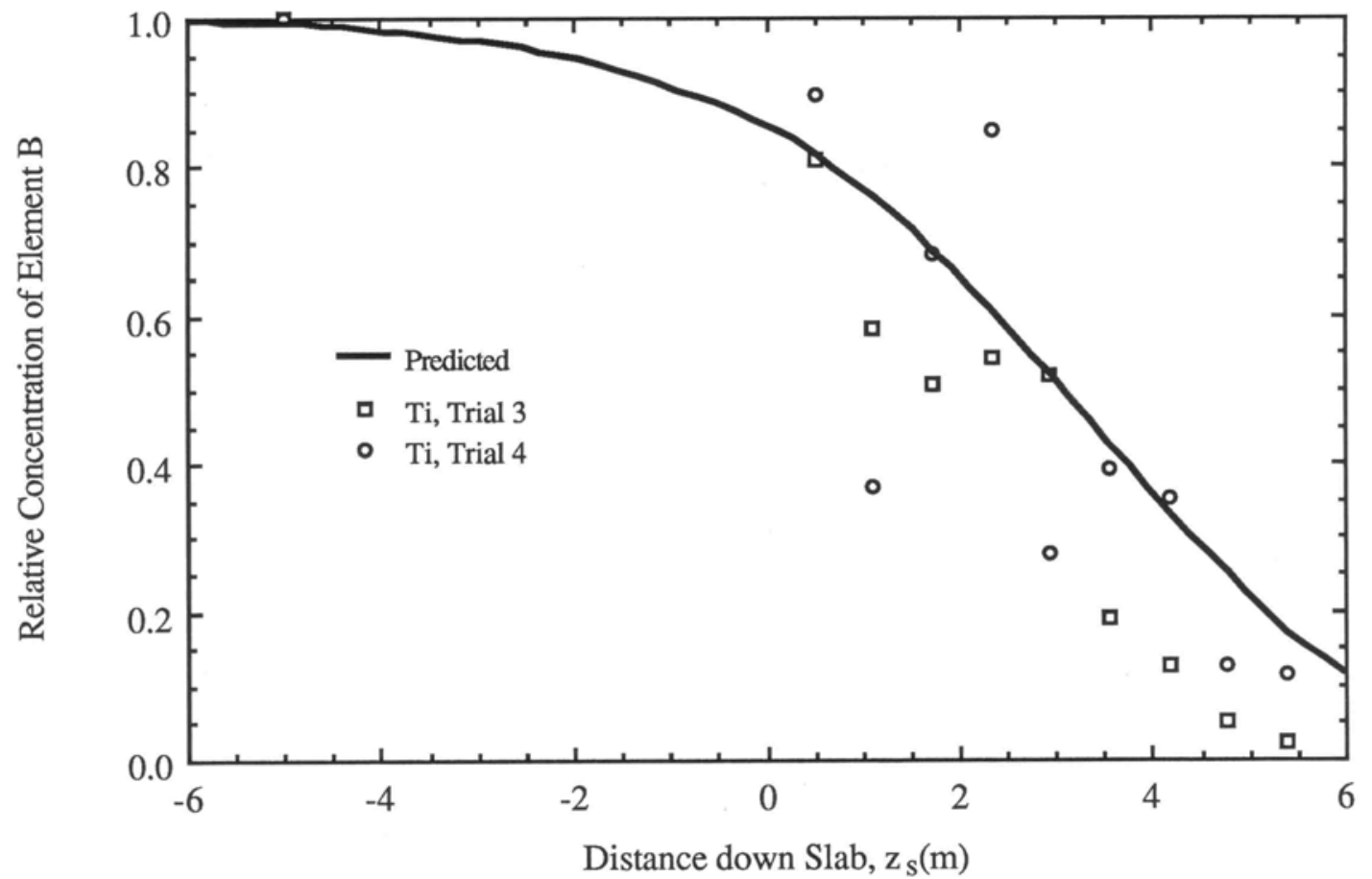

FIG. 13. Comparison between predicted and measured ${ }^{[2]}$ relative concentration of element B along slab centerline. 


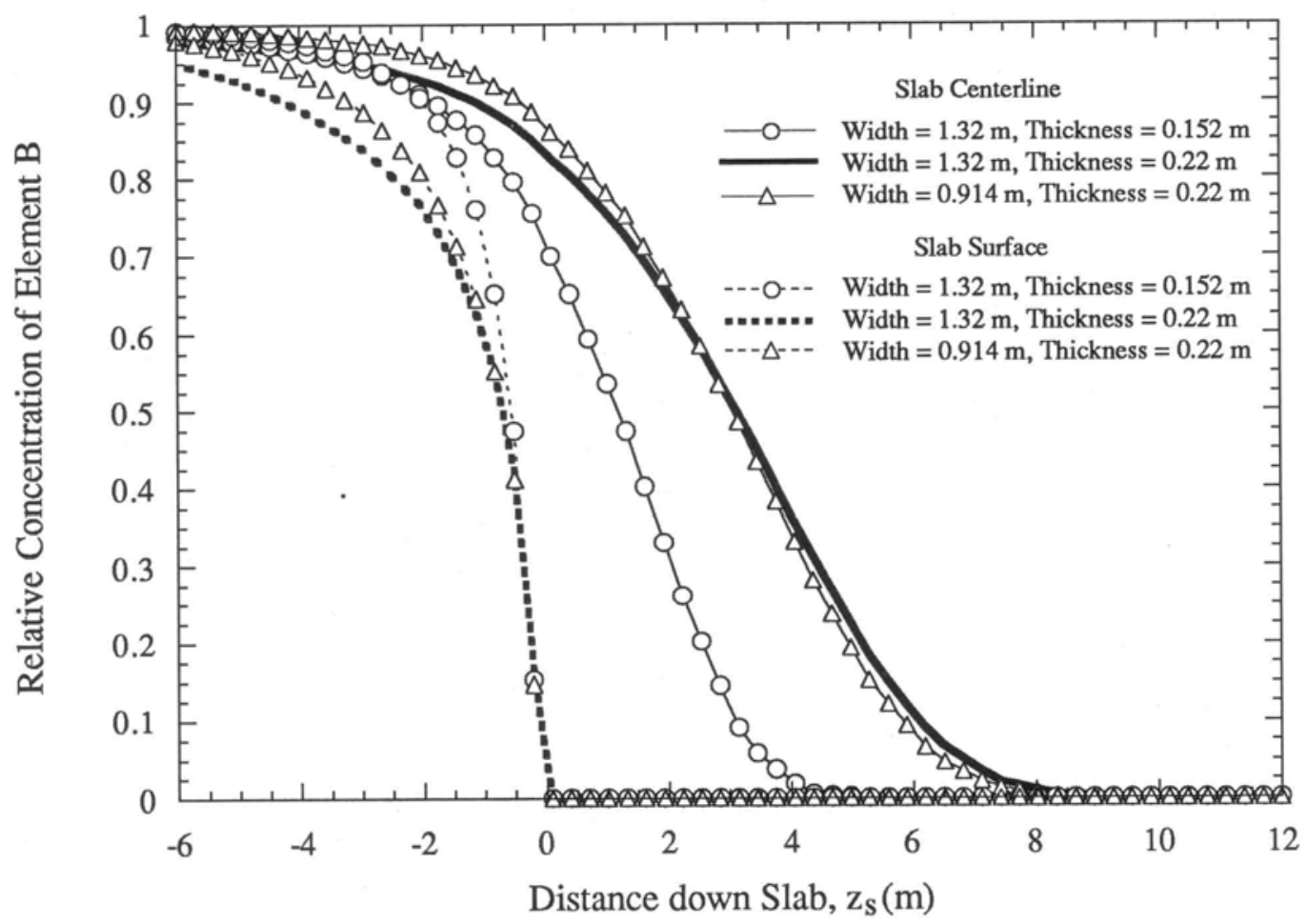

FIG. 14 Effect of mold dimensions on slab composition. 


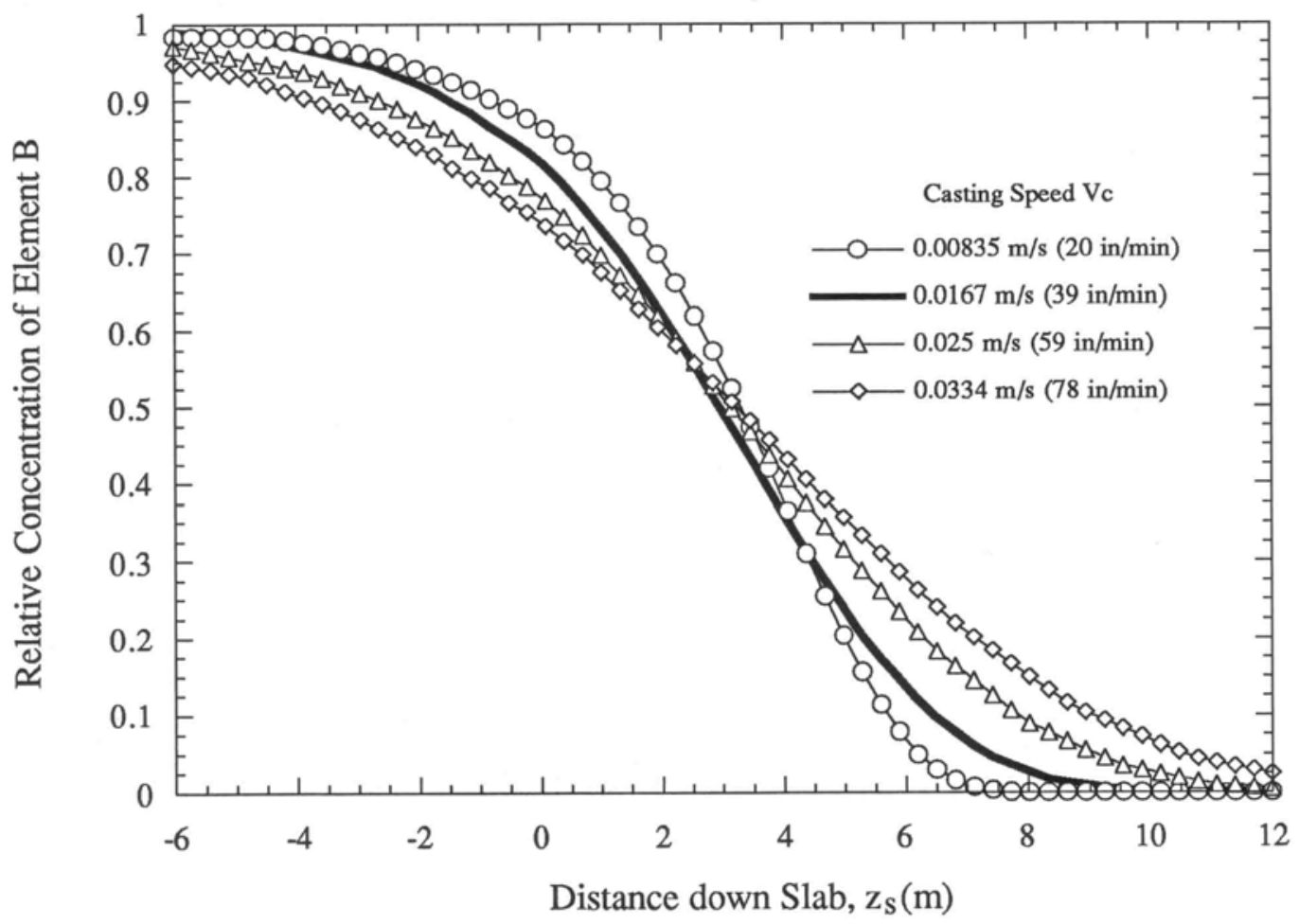

FIG. 15 Effect of casting speed on composition along slab centerline. 


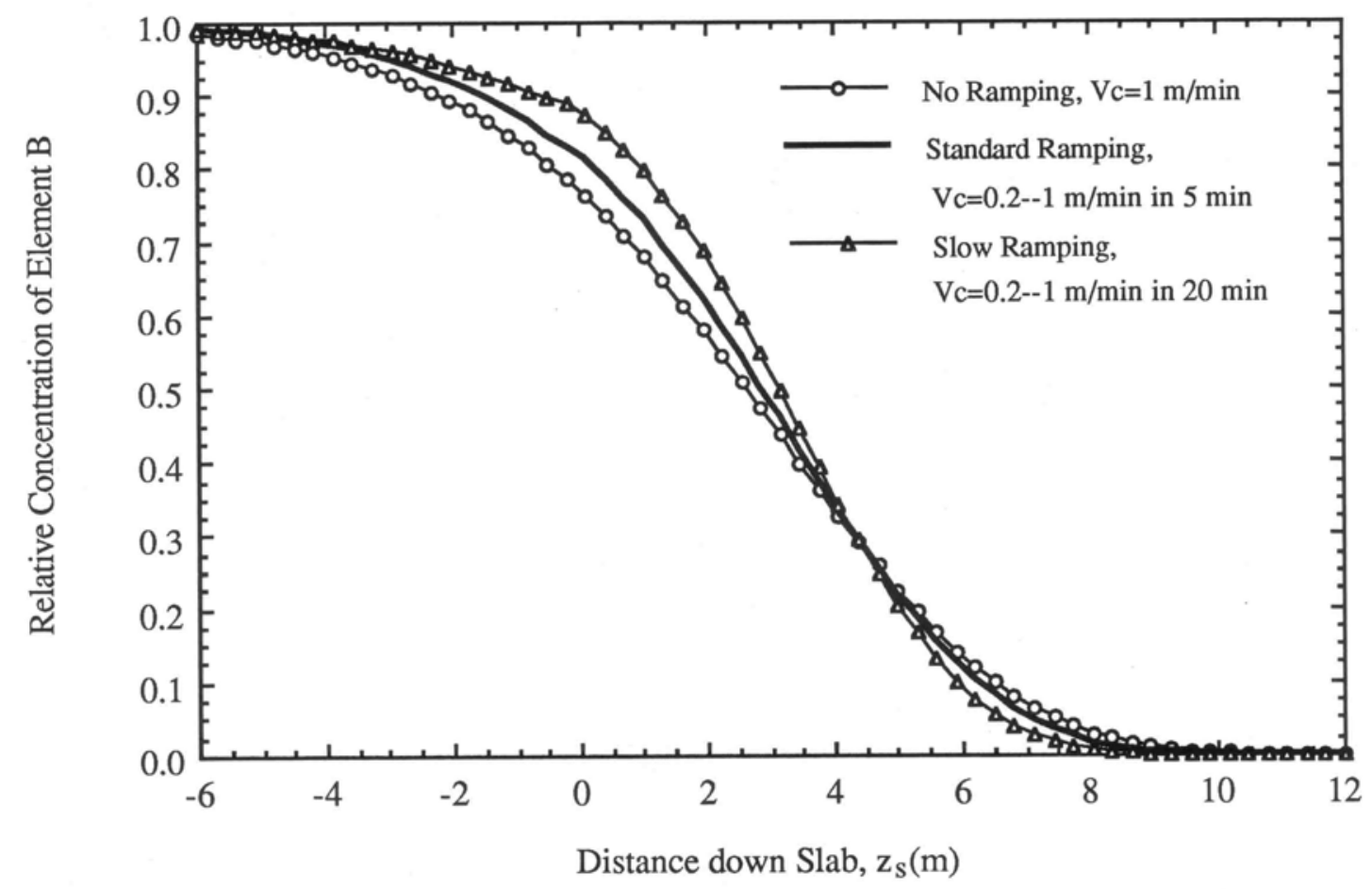

FIG. 16 Effect of ramping of casting speed on composition along slab centerline.

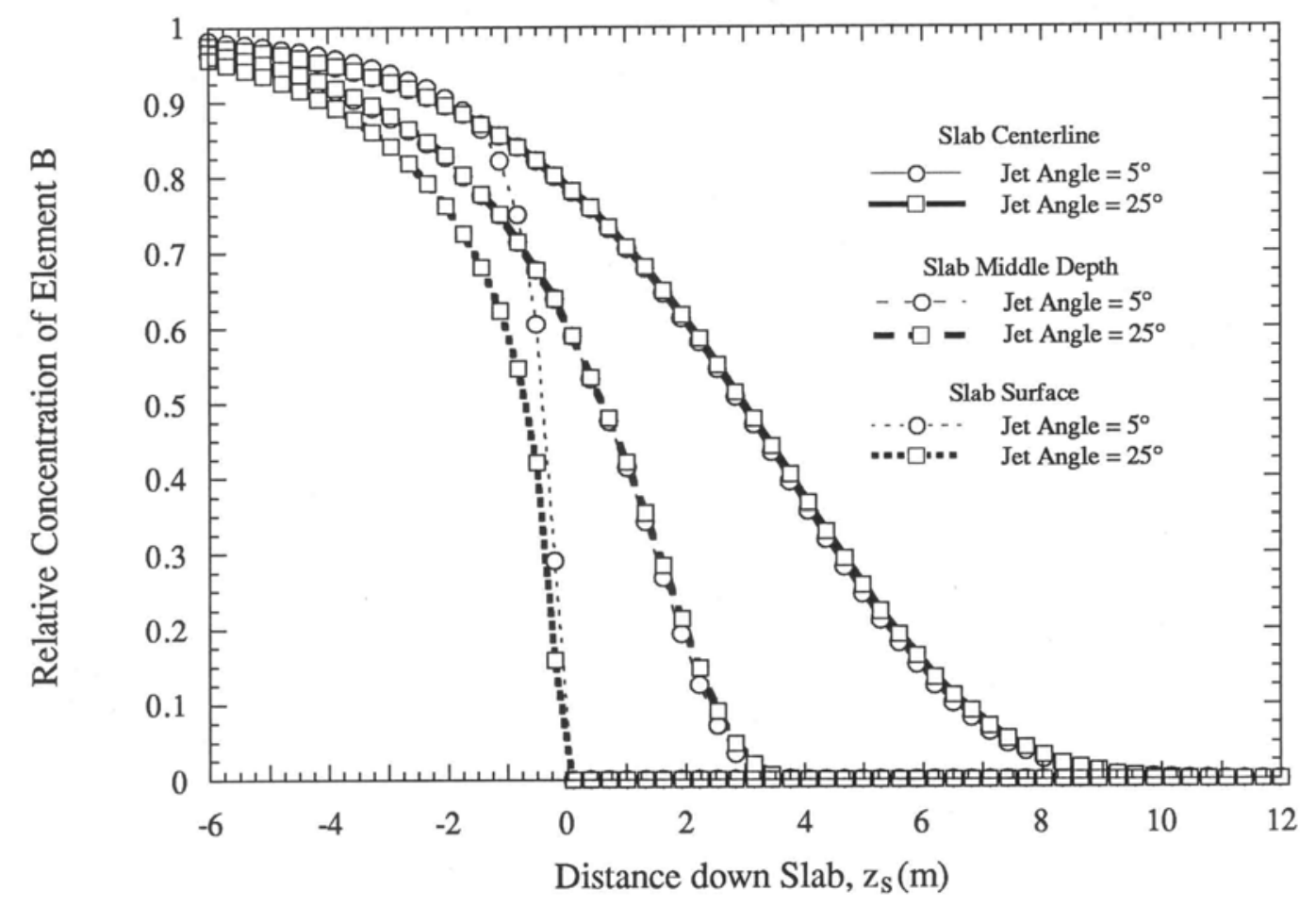

FIG. 17 Effect of jet angle from nozzle on slab composition. 